\title{
LA NECRÓPOLIS TARDO-ANTIGUA DEL TOSSAL DE LES BASSES (ALICANTE, ESPAÑA): TIPOLOGÍA Y PRIMERA APROXIMACIÓN INTERPRETATIVA Y CRONOLÓGICA
}

Se presenta en este artículo un resumen del estudio pormenorizado que hemos realizado sobre una necrópolis tardo-antigua, que no ha podido vincularse con ningún núcleo urbano de importancia. Su desarrollo desde mediados del s. IV hasta la llegada de los musulmanes a inicios del s. VIII, hacen a esta necrópolis fundamental para entender la evolución de la zona con posterioridad a la desaparición en el s. III de la ciudad romana de Lucentum.

Palabras clave: Alicante, tardo-antigüedad, necrópolis, cronología, cristianismo.

The Late Antique Necropolis of Tossal de les Basses (Alicante, Spain): Typology and First Interpretative and Chronological Approach

Summary of detailed study we performed on a late ancient cementery were unable to link to any town of importance. Its development since the middle of s. IV until the arrival of the Muslims at the beginning of s. VIII, makes this fundamental necropolis for understanding the evolution of the area after the disappearance in s. III of the Roman city of Lucentum.

Key words: Alicante, Late Antiquity, cementery, chronology, Christianity.

La necrópolis del Tossal de les Basses, ya se había documentado en las campañas de excavación llevadas a cabo por nosotros en los años 1990 y 1992 (Rosser 1994: 69-110; Rosser y Pérez Burgos 2003: 177-194), más concretamente junto al llamado Camino del Chinchorro, en el que se encontró (en la primera campaña) una tumba de inhumación con cubierta de grandes losas de piedras, y (en la segunda) 11 individuos completos, en fosas simples excavadas en la tierra con cubrición de grandes losas planas y estructuras semi-tumulares. Por lo tanto, sumando estas 12 tumbas con las 805 documentadas en las últimas campañas realizadas desde el año 2004, tendríamos, por ahora, y a la espera de poder terminar de excavar toda la zona potencial de necrópolis, un total de 817 tumbas, que no enterramientos, como quiera que algunas tumbas aparecen reutilizadas una o más veces.
No nos detendremos aquí en lo relativo a los espacios ocupados que se producen en el Tossal de les Basses en época tardo-antigua, sólo nos centraremos en los aspectos relativos al mundo funerario de estas gentes, y en su reflejo en la cultura material. En cualquier caso, los asentamientos de donde pudieron proceder algunas, aunque no todas, las personas allí enterradas pudieron ser, básicamente, la Villa o instalación de los Sectores 3, 4, 5 y 7, en donde se documentan estructuras y un registro material entre los ss. III al VI d.C., fundamentalmente. También estaría el vicus inmediatamente posterior, esto es, de los ss. VII a la 1a 1/2 del VIII d.C., en el Sector 8.

Existen otras zonas en la Albufereta con asentamientos de época tardo-antigua, pero en la mayoría de los casos se asocian a sus propias áreas cementeriales por lo que, en principio, no habría que pensar que la necrópolis 


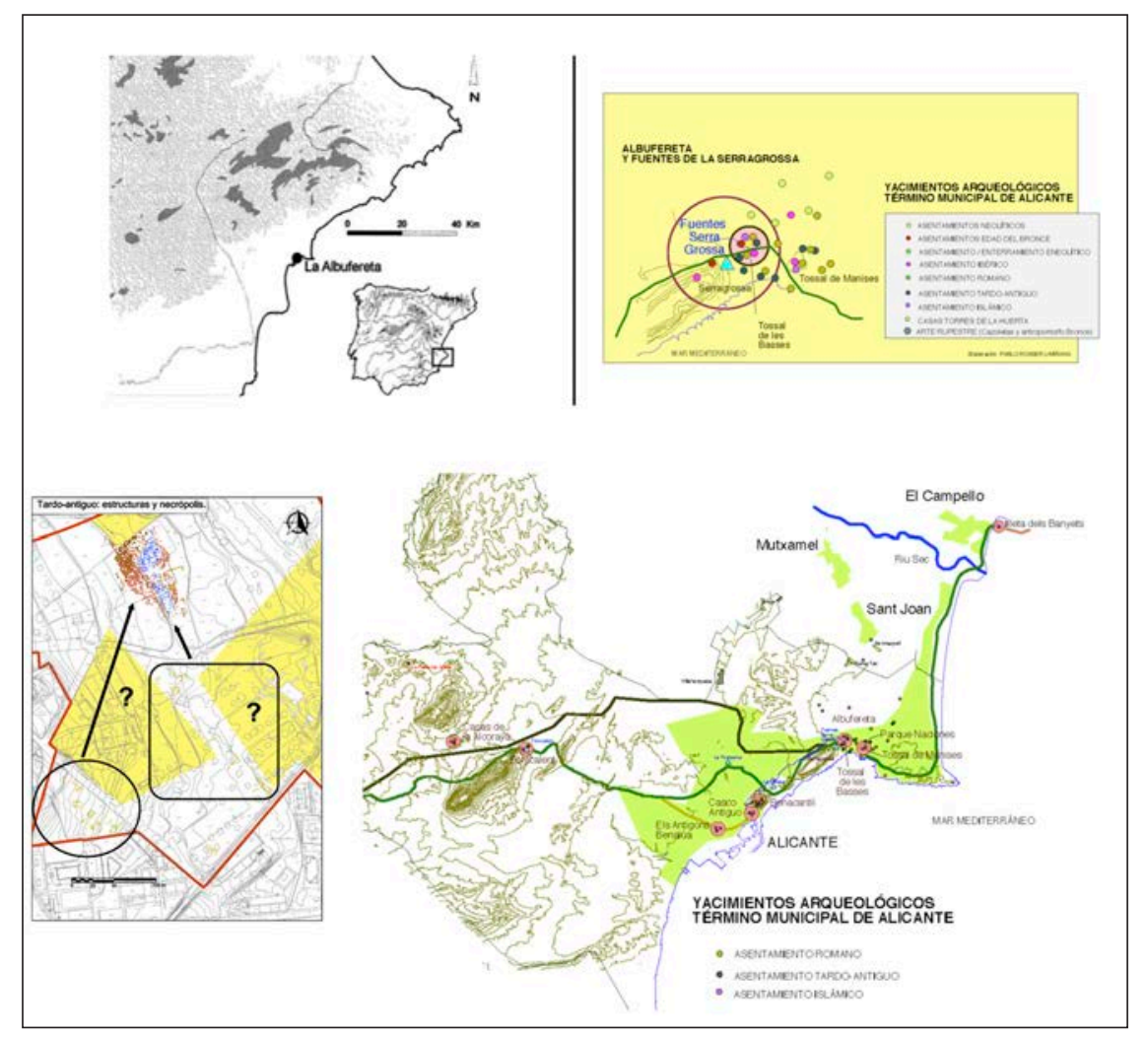

Fig. 1. Zonas con asentamientos tardo-antiguos cercanas al área de la necrópolis principal documentada: Sectores 3, 4, 5 y 7 , por un lado, con estructuras y registro material desde el s. III hasta al menos el s. VI. Y Sector 8 (en la parte inferior izquierda del plano), con un asentamiento inmediatamente posterior: $\mathrm{s}$. VIIVIII d.C. Tanto para esta figura como para el resto, remitimos a la versión online para una correcta visualización de los colores.

que tratamos lo fuera de toda el área. Asentamientos como Casa Ferrer o Parque Naciones, por ejemplo, tienen sus tumbas asociadas.

Es cierto que, recientemente, se ha reclamado una mayor precaución a la hora de hablar de grandes necrópolis rurales: Tampoco es cierto que los hábitos funerarios de los siglos VI y VII se expresen únicamente mediante grandes necrópolis ubicadas en una posición central respecto a diversos asentamientos más o menos alejados y convertidas, de esta manera, en escenario simbólico de rivalidad y emulación social (Azcárate y Solaun 2003). Para Halsall (1995: 248) the cemetery as an arena for competitive discourse, with the burials as statements. Por su parte, Perin subrayaba que los casos de cementerios comunes a diversos hábitats no constituyen la regla (1998: 171). Azcárate, refiriéndose a la zona del actual País Vasco insistirá en lo mismo (Azcárate 2004).

En cualquier caso, y aunque hasta ahora se ha defendido para el País Valenciano la ausencia absoluta en él de grandes cementerios que denotarán la existencia de aglomeraciones urbanas secundarias o hábitats agrupados de tipo vici (González Villaescusa 2001: 128), creemos que es momento de revisar dicha afirmación a la luz de nuestros hallazgos en el Tossal de les Basses, toda vez que cementerios como los de la Casa Calvo con 21 enterramientos, Horta Major con más de 30, Bernissa con más de 50, Mas del Pou con 63, Vistalegre con 64 y El Albir con más de 150 sepulturas, quedan muy por debajo de la cifra que actualmente barajamos para nuestro yacimiento, esto es, en torno al millar de enterramientos.

Cabría la posibilidad de estar ante un cementerio, por lo tanto, de un único núcleo poblacional, esto es, la villa -o villas- e instalaciones anexas existentes en la zona del propio yacimiento, aunque también podríamos estar ante un cementerio común a uno o varios establecimientos rurales (Ribera 1992: 66), como también se ha documentado en la Galia ${ }^{1}$.

Los paralelos a nuestro cementerio habría que buscarlos, en cualquier caso, en los llamados periféricos pero de especial rango, como puede ser el caso del mausoleo del Camí del Molí dels Frares, o de St. Vicent de la Roqueta, o, también el situado en torno a la basílica de la Alcudia de Elche. Fuera de nuestro territorio, un paralelo podría ser el del cementerio de la basílica de Vega del Mar (Málaga). 


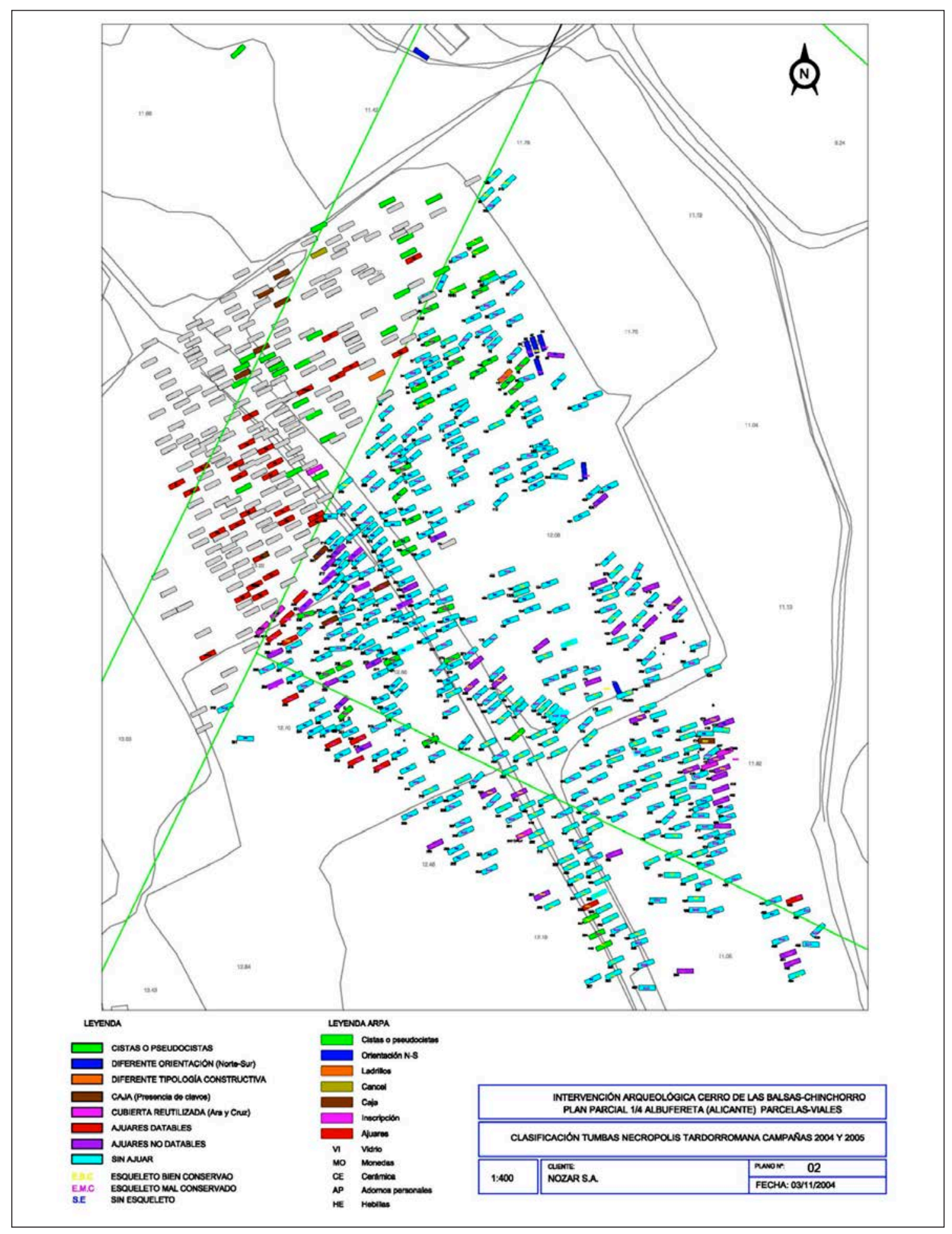

Fig. 2. Planimetría de la necrópolis con las distintas variaciones de tumbas, depósito funerario, etc. 


\section{TIPOLOGÍA CONSTRUCTIVA DE LAS TUMBAS}

La no existencia de estratigrafía vertical en la necrópolis, ni de superposiciones de estructuras de enterramiento, no nos permiten hacer otro análisis cronológico que el relativo a la tipología constructiva de las tumbas, en su relación con las dataciones absolutas y el registro material exhumado en su interior. Es por ello que empezaremos por establecer dicha tipología.

Es muy diversa la tipología existente a la hora de clasificar los distintos tipos constructivos en la necrópolis debido, lógicamente, al importante número de tumbas exhumadas. Se trata, en cualquier caso, de fosas simples, de forma oval y excavadas en la tierra y/o roca, que cortan a niveles romanos, ibéricos, de la Edad del Bronce y neolíticos y que, en ocasiones, alcanzan el nivel estéril. Existen tumbas con una cubierta, con dos o, incluso, con tres, predominando las de losas, piedras/losas y piedras/piedras/losas, algunas con restos de pavimentos, de opus signinum e, incluso, algún fragmento de mosaico reutilizado. En la mayoría, no existe un acondicionamiento del espacio sepulcral, depositándose el cuerpo directamente sobre la tierra en decúbito supino, aunque sí que hay algún ejemplo de cista con revestimiento de losas de piedra en toda la fosa, o pseudocista con losas sólo en la cabecera, o bien a los pies de la tumba e, incluso, se ha constatado la existencia de cajas de madera o simples parihuelas, que identificamos por la presencia de clavos de hierro en el interior de la fosa.

Se han estudiado para este trabajo 554 de las 817 tumbas que se han excavado (el $68 \%$ del total). No se ha podido abordar el estudio de todas ellas por encontrarse aún en proceso de elaboración los datos del resto. No obstante, se trata de una cifra considerable para lo que viene siendo habitual en estudios de necrópolis en las tierras del SE peninsular².

Debido sobre todo a acciones agrícolas de época moderna y de zanjas para tuberías en época contemporánea, muchas de estas tumbas se han visto afectadas, sobre todo en cuanto a la conservación de sus cubiertas. Es por ello que se tuvo que crear un tipo 0 que, si bien no es significativo en cuanto a características constructivas, evita distorsiones en las estadísticas que hemos elaborado. El número de tumbas afectado, del total de estudiadas, es alto, llegando a la cifra de 111 (20\% del total).

Si excluimos al tipo 0 , tendríamos, por lo tanto, un estimable $44 \%$ de tumbas con tipo concreto definido, lo que nos permitirá hacer numerosas reflexiones e intentar establecer una serie de hipótesis de trabajo e, incluso, conclusiones sobre lo que estos tipos significan en la necrópolis, su cronología, distribución espacial en el tiempo, el depósito funerario que se le asocia, etc.

Para el establecimiento de los tipos hemos seguido criterios exclusivamente formales, poniendo en relación tipos de cubierta (tierra, túmulo de piedras medianas o pequeñas, losas de piedra, etc.) y su orden de colocación, en el caso de que aparezcan varios de ellos juntos. Una vez establecido este criterio se conjuga con el tratamiento interior de la fosa (simple, con cistas o seudo-cistas, ladrillos, etc.).

El tipo de cubierta usado predominantemente es el de lajas de piedra (tipo I), con un abrumador $48 \%$. Le sigue, el tipo II (túmulo/ cubierta de piedras), con un $41 \%$, quedando ya en usos menores los tipos III (cistas, con un $11 \%$ ), IV (ladrillos, con un 1\%), y V (paquete huesos sobre tumbas, con un $1 \%$ ).

Volviendo a las tipologías, la unión del tratamiento de cubiertas e interior de las fosas, nos ha permitido crear, incluyendo al tipo 0 , seis tipos distintos que vienen identificados en números romanos. Las posibles variaciones en cada uno de los tipos son consideradas subtipos, y se nominan con letras mayúsculas correlativas. En algunos casos, como el tipo III, y debido a su complejidad constructiva, se han creado variaciones dentro de los subtipos, que vienen reflejadas por letras minúsculas.

Como se irá viendo a lo largo de este análisis, y del tratamiento estadístico que de él haremos, los tipos mayoritarios, en principio (y excluyendo el tipo 0), son aquellos que tienen mayor simplicidad constructiva, y en donde aparecen dos variables distintas, o bien lajas de piedra como única cubierta, o bien el binomio túmulo/ lajas de piedra. Efectivamente, se tratan del tipo IA $(\mathrm{Cu}-$ bierta de lajas de piedras, que apoya sobre la fosa, con un $22 \%$ del total estudiado), o el tipo IB (Cubierta de lajas de piedras, que apoya sobre banco lateral o pre-fosa, con un 16\%), el tipo IIE (túmulo/cubierta de piedras sobre lajas que se apoyan sobre banco lateral de la fosa, con un $11 \%$ ), y el tipo IIC (túmulo/cubierta de piedras bajo el que se encuentran lajas de piedra, con un $9 \%$ ).

Este hecho habría que interpretarlo en dos sentidos: por un lado, en la posible "necesidad" de "ahorro" y simplicidad constructiva, que es la tendencia mayoritaria del ser humano a la hora de construir, pero también por el menor coste económico que ello produce (entendido "coste económico" al menor número de trabajadores necesarios, así como de elementos de construcción y herramientas utilizados, y no tanto por lo que hubiera que desembolsar en dinero en metálico). 
Fig. 3. Algunos Tipos y sub-tipos constructivos de las tumbas del Tossal de les Basses.

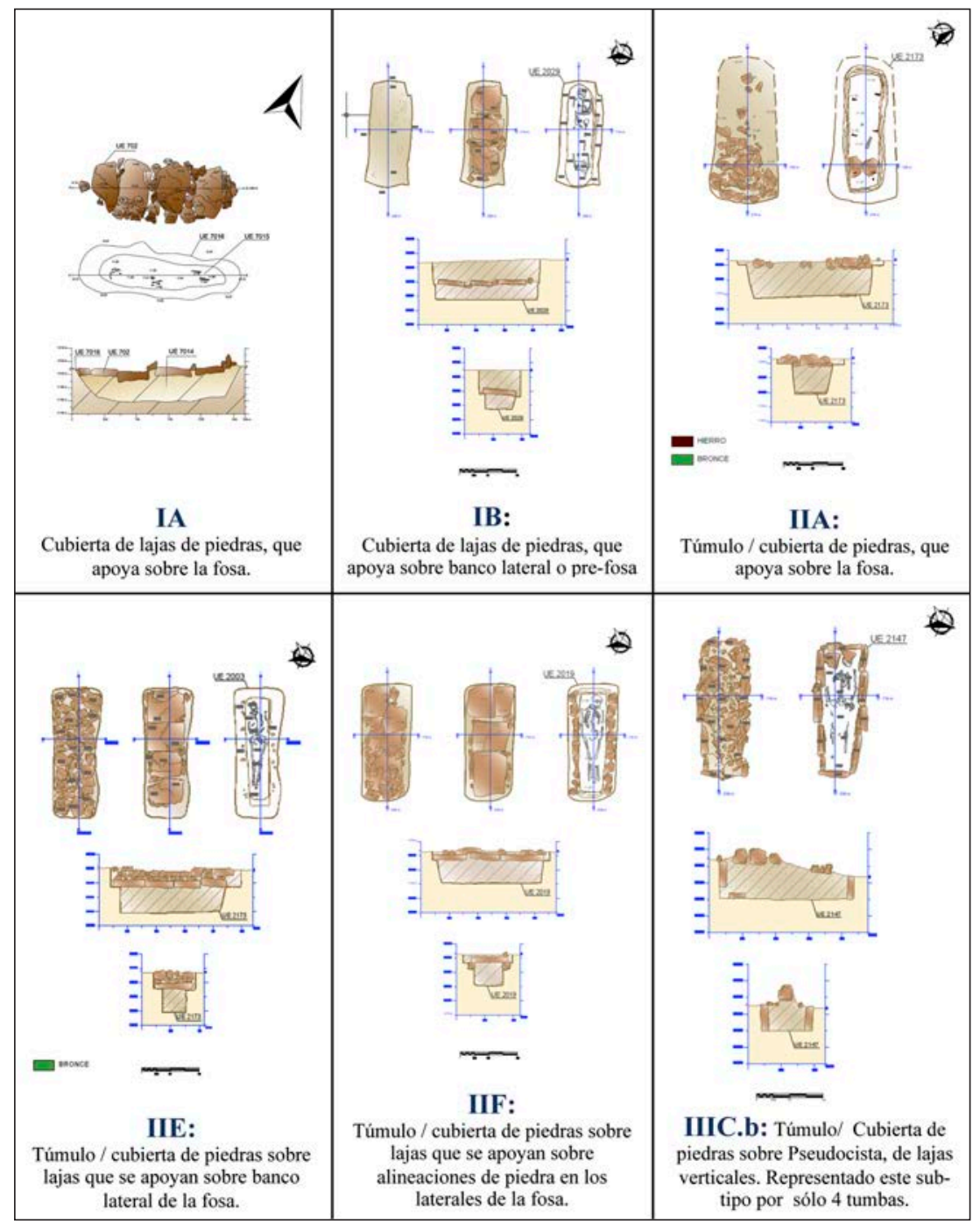

El hecho de que, incluso, algunas tumbas hayan sufrido reutilizaciones desde la primera vez que se construyeron (con el consiguiente trabajo de destrucción y reconstrucción, sobre todo de la cubierta) debe también tenerse en cuenta como factor determinante a la hora de elegir este tipo de cubierta más genérica.

Siendo cierta esta máxima, también existen excepciones que confirman la norma, o que abren la posibilidad de otras, o variadas explicaciones. Así, un tipo extremadamente sencillo -aparentemente al menos- como es el tipo IIA (túmulo/ cubierta de piedras, que apoya sobre la fosa), sólo es utilizado un 5\%, o el tipo IIB (túmulo/ cubierta de piedras sobre banco lateral de la fosa), con sólo un $3 \%$.
Cabría plantear, en estos dos casos, que la sencillez constructiva extrema, sin embargo, se ve encarecida por la necesidad de utilizar caja o ataúd de madera (como hemos podido comprobar por la existencia de clavos localizados fundamentalmente en extremos o zonas laterales). Muy probablemente ésta sea una explicación plausible: el encargo de un ataúd de madera quizá no estaba al alcance de todas las familias que usaron la necrópolis.

No obstante lo dicho, y a partir de estos tipos fuerza, se documentan una serie de variaciones interesantes no sólo respecto al posible ritual y simbología que de ello se pudiera derivar, sino también en relación al momento cronológico en el que se produce el fallecimiento del 


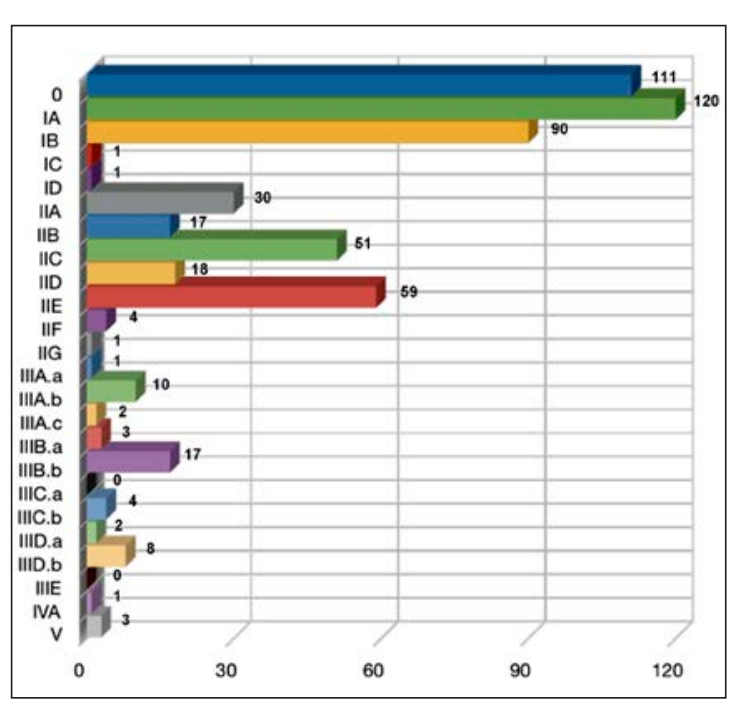

Fig. 4. Gráfico de tipos, subtipos y número de tumbas por tipo. Elaboración: Pablo Rosser.

individuo y su entierro. No es descabellado pensar en la existencia de "modas" constructivas según en momento cronológico en el que se construyen las tumbas. Del mismo modo, tampoco es descartable, y se puede observar simplemente viendo la localización de las tumbas, cómo algunos tipos, subtipos o variaciones tienen también que ver con relaciones familiares o de clan.

En cualquier caso, es muy difícil concluir, sin riesgo a equivocarse, cuál de estos criterios es el que imperó a la hora de construirse un tipo u otro, pudiendo incluso haber afectado en la decisión varios, o todos los factores propuestos.

\section{ENCUADRE CRONOLÓGICO POR TIPOS CONS- TRUCTIVOS}

Gracias, sobre todo, a las dataciones absolutas que hemos ido obteniendo ${ }^{3}$, vamos a establecer, grosso modo, un encuadre cronológico de las tumbas y sus tipos constructivos, fundamentalmente en cuanto a los inicios de sus usos y su dispersión a lo largo del tiempo de uso de la necrópolis. Quedará, posteriormente y como hemos dicho más arriba, el contrastar esta información con la que proporcionan los depósitos funerarios y la distribución espacial de las tumbas en la necrópolis, momento en el que intentaremos concretar -más aún si cabe- su cronología.
En primer lugar, hay que decir que consideramos como desviaciones cronológicas que, en principio, no vamos a tener en cuenta en nuestro análisis las dataciones obtenidas para algunas de las tumbas. Más claramente será así para la tumba 414 (Tipo I, cal 50 a.C.) y, con algunas dudas, para la tumba 409 (Tipo I, cal 80 d.C., aunque con una dispersión entre cal 10-210 d.C.). Al igual que en un enterramiento tardo-antiguo se obtuvo una datación neolítica, de un enterramiento de esta época situado por debajo del nuestro, otras dataciones alto-imperiales se podrían relacionar con incineraciones de ese momento cronológico, muy documentadas en el yacimiento.

Con todos los datos anteriormente expuestos (Tipologías y dataciones absolutas de las mismas), y a partir de la tabla siguiente (fig. 5), se han confeccionado unos gráficos de dispersión, de los que a continuación sacaremos las conclusiones más importantes.

Si nos detenemos en el gráfico de la figura 6, puede observarse que debió existir cierta relación entre tipos y momentos en que se produjo el enterramiento. Ello es más difícil de precisar para aquellos tipos generales, como el IB, que tienen lógicamente un uso más continuado en el tiempo. Hasta tal punto esto es así que, como veremos mas adelante, el tipo IB no sólo lo encontramos en el s. IV d.C., sino que perdura hasta principios del s. VIII d.C. (esto es, últimos momentos de la ocupación hispano-visigoda) e incluso se documenta para las primeras tumbas de época islámica (cal. 890 d.C.).

En el gráfico de la figura 7, es donde más claramente podemos comprobar la relación comentada más arriba entre tipos y dataciones absolutas. Así, y teniendo en cuenta que se han grafiado sólo los momentos iniciales de utilización de cada tipo, obviando su dispersión cronológica, es más fácil observar la posible existencia de cuatro grandes momentos en el inicio de la construcción de los distintos tipos de enterramientos. No obstante, hay que dejar claro que se trata de una aproximación sólo a los inicios del uso de cada tipo, lo que no significa que sólo se den en dicha fase, ni que no existan -por lo tantoen las siguientes, como ya hemos comentado por ejemplo para el tipo IB, aunque no sólo para él. Sí que es cierto, y se verá seguidamente, que hay algunos tipos o subtipos que sólo se documentarán en una fase, lo cual tiene mucho interés.

- FASE $1^{\text {a }}$ de inicio de tumbas: fechada, en base a cronologías absolutas, a mediados del s. IV d.C., está representada, fundamentalmente, por el tipo IB (cubierta de lajas de piedra sobre banco lateral), que perdurará mucho en 


\begin{tabular}{|c|c|c|c|}
\hline TIPO & CRONOLOGIA & TIPO & CRONOLOGIA \\
\hline $\mathbf{0}$ & 640 & IIC & 650 \\
\hline $\mathbf{0}$ & 570 & IIC & 575 \\
\hline $\mathbf{0}$ & 420 & IIC & 590 \\
\hline $\mathbf{0}$ & 250 & IIC & 560 \\
\hline IA & 710 & IID & 540 \\
\hline IA & 790 & IIE & 400 \\
\hline IA & 690 & IIE & 410 \\
\hline IA & 620 & IIF & 660 \\
\hline IA & 490 & IIF & 550 \\
\hline IA & 550 & IIIA. a & 610 \\
\hline IB & 670 & IIIB. a & 550 \\
\hline IB & 610 & IIIB. b & 540 \\
\hline IB & 570 & IIIB. b & 570 \\
\hline IB & 410 & IIIC. b & 540 \\
\hline IB & 340 & IIID.a & 420 \\
\hline IB & 640 & IIID. b & 400 \\
\hline IB & 650 & IVA & 530 \\
\hline IB & 700 & \multicolumn{2}{|l}{} \\
\cline { 1 - 3 } & & &
\end{tabular}

Fig. 5. Tabla de tipos y dataciones absolutas, eliminando dataciones que no corresponden directamente a enterramientos tardíos, aunque dejando las posiblemente islámicas. Dataciones realizadas por Beta Analytic Radiocarbon Dating Laboratory. Miami, Florida. EEUU. Fechas calibradas 2 sigma con el programa INTC AL04.

el tiempo por ser, quizá, uno de los más simples desde un punto de vista constructivo. Efectivamente, algunas tumbas de este tipo han dado una cronología temprana: la tumba 493 (cal. 340 d.C.), mientras que otras llegan a momentos previos a la ocupación islámica o, incluso, pudieran ser de época islámica. Por ejemplo, la tumba 2110 ( ca. 650 d.C.), la tumba 2133 (cal. 700 d.C.), de la tumba 249, que se fecha $c a .670$ d.C.).

- FASE 2a: se produce un crecimiento de la necrópolis en el inicio de tipologías constructivas diversas, aunque relativamente, como ahora veremos. Con independencia de la perduración del tipo IB de la fase anterior, podemos asignar unos nuevos tipos, claramente, a esta fase (IIID.b, IIE. IIIDa). Por cronologías absolutas estaríamos desde inicios a mediados del s. V d.C. Tienen los tres tipos un denominador común que les hacen, prácticamente, iguales, esto es: el presentar túmulo de piedras por encima de lajas de piedra, variando sólo en cuanto a si tienen cista o no, o banco lateral. Por lo tanto, habría que pensar que el "fósil director" de este periodo es el complemento túmulo

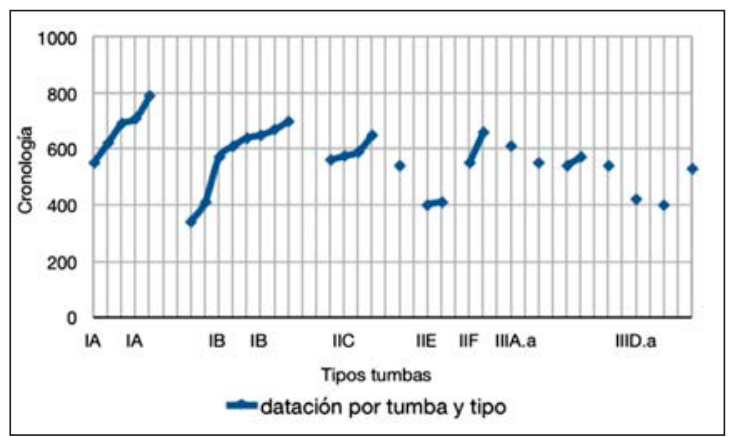

Fig. 6. Tumbas por tipos y dataciones absolutas.

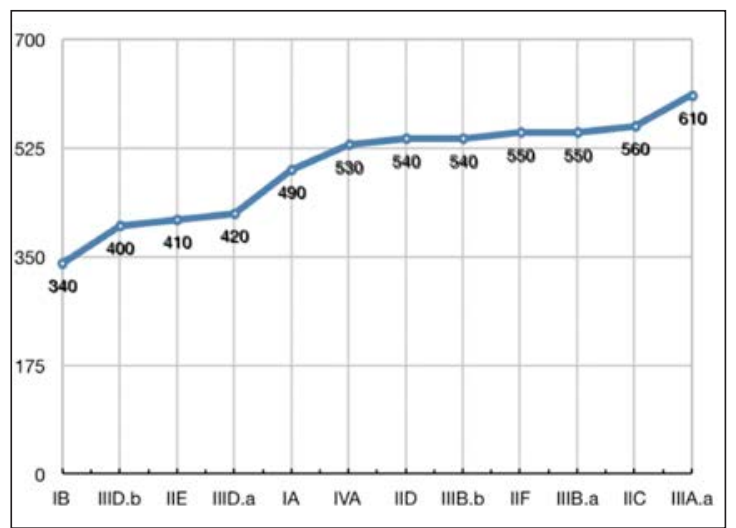

Fig. 7. Evolución diacrónica de tipos.

sobre laja de piedras. Además, la mayoría de estos tipos no presenta perduración en el tiempo, sólo el tipo IIE sobrepasa los doscientos años, por lo que quedaría encuadrado entre esta fase de la secuencia y las $3^{\mathrm{a}}$ y $4^{\mathrm{a}}$. En algunos casos (tumba 2047, del tipo IIIDb), vuelven a aparecer elementos reutilizados (cancel), pero siempre iniciado el s. V d.C.

- FASE TRANSICIÓN 2/3: se trata de lo que podríamos considerar una sub-fase o una fase de transición, en donde sólo tendríamos el inicio del uso del tipo IA que, al igual que pasaba con el IB, se prolonga mucho en el tiempo, por su sencillez constructiva (cubierta de lajas sobre fosa). Se fechan sus inicios a finales del s. V d.C., si bien perdura hasta época islámica su uso.

- FASE 3 a: se produce ahora una mayor variedad de inicio de tipos (IVA, IID, IIIB .b, IIIC.b, IIF, IIIB .a, IIC). Se encuadran durante, prácticamente, todo el s. VI d.C., y principios del VII d.C. La perdurabilidad de los tipos es muy escasa (sólo el tipo IIF llega a los cien años de uso), y se circunscribe a esta fase, lo que -al igual que ocurría con 


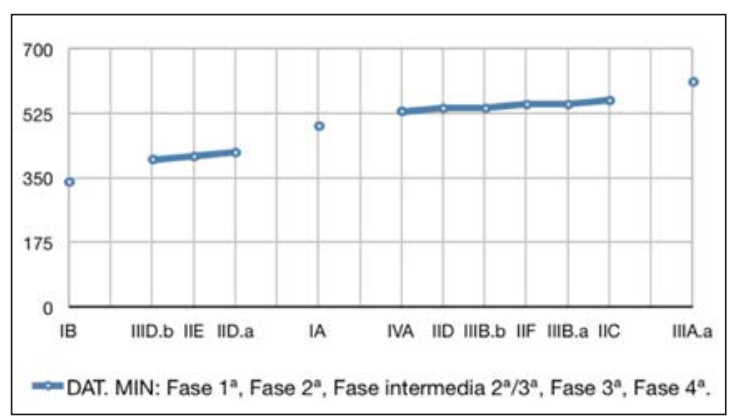

Fig. 8. Agrupación de tipos por fases.

la $2^{\text {a }}$ fase- existe una gran coherencia en la conformación de la misma. Se inicia esta etapa con el tipo IVA (ladrillos planos), que era el usado en la cercana necrópolis de las Torres. Quizá no sea casualidad, y haya que interpretarlo como que la necrópolis que nos ocupa se inicia con "la moda" de aquella (aunque con un sólo ejemplo documentado por ahora), si bien rápidamente incorpora otros tipos. Alguno de esos tipos, siguiendo la tradición de la fase $2^{\mathrm{a}}$, en cuanto al uso de cubiertas de túmulo sobre losas de piedra, aunque con ligeras variaciones (tipo IID, IIF y IIC). Otras tumbas mantendrán el túmulo, pero eliminando la cubierta inferior de lajas (tipo IIICb). Sin embargo, en seguida aparecen nuevos tipos en donde ya ha desaparecido el túmulo (tipos IIIBa, IIIBb). Quizá el elemento novedoso, y denominador común de la mayoría de esos tipos y, por lo tanto, "fósil director" de esta $3^{\text {a }}$ fase sean las cistas, sobre todo verticales. Aparecen en, al menos, tres de los siete tipos documentados, pudiendo unir un cuarto tipo si considerásemos a los ladrillos verticales del tipo IVA como "cista” y, quizá, su precedente y al que imitan. Subrayaremos, por último, la aparición sobre una tumba (352) del citado tipo IIC, de un claro signaculum con cruz griega incisa sobre la piedra.
- FASE 4a: y último momento documentado en cuanto al inicio de tipos constructivos, correspondería a sólo un tipo (IIIAa), que se fecharían por cronologías absolutas en los inicios del s. VII d.C. No es descartable que no se trate de un nuevo tipo, sino uno de los citados para la fase anterior y que ha perdido la cubierta, pero hemos preferido reseñarlo aparte. Si tenemos en cuenta la datación mínima (fig. 5) podríamos pensar que es un tipo evolucionado en el tiempo, como quiera que es el que presenta una datación más moderna. Sin embargo, si observamos la dispersión de los tipos por fases (fig. 9), observamos que al menos dos tipos de la fase anterior (IIF, IIC) incluso superan la datación del tipo IIIAa, llegando a 1/2 del s. VII d.C., prácticamente al final del uso de la necrópolis.

Posteriormente, habrá una utilización de carácter residual y, en algunos casos reutilizando tumbas anteriores, que fechamos entre finales del s. VII y s. VIII, y que relacionamos con la transición entre el mundo hispano-visigodo y el musulmán, que además tendrán sus propios cementerios.

Por lo tanto, y como parece quedar claro en el gráfico de la figura 8 , sí podemos hablar a grandes rasgos $-\mathrm{y}$ a falta de confirmación con el contraste de depósitos funerarios y distribución espacial- de cinco fases, o cuatro y una intermedia entre la $2^{\mathrm{a}} / 3^{\mathrm{a}}$, que abarcarían desde $1 / 2 \mathrm{del}$ s. IV hasta prácticamente el s. VIII d.C.

Pero hemos comprobado más arriba que existe una dispersión de algunos tipos que, a priori, no nos permiten ajustar subtipos a cronologías. Efectivamente, y como se observa en la correspondiente tabla y gráfico (fig. 9), y a partir de las dataciones absolutas mínimas y máximas, podemos ver cómo los subtipos a IB, IIE, IA, y IIC presentan horquillas cronológicas que abarcan dos, tres o, incluso, las cuatro fases propuestas.

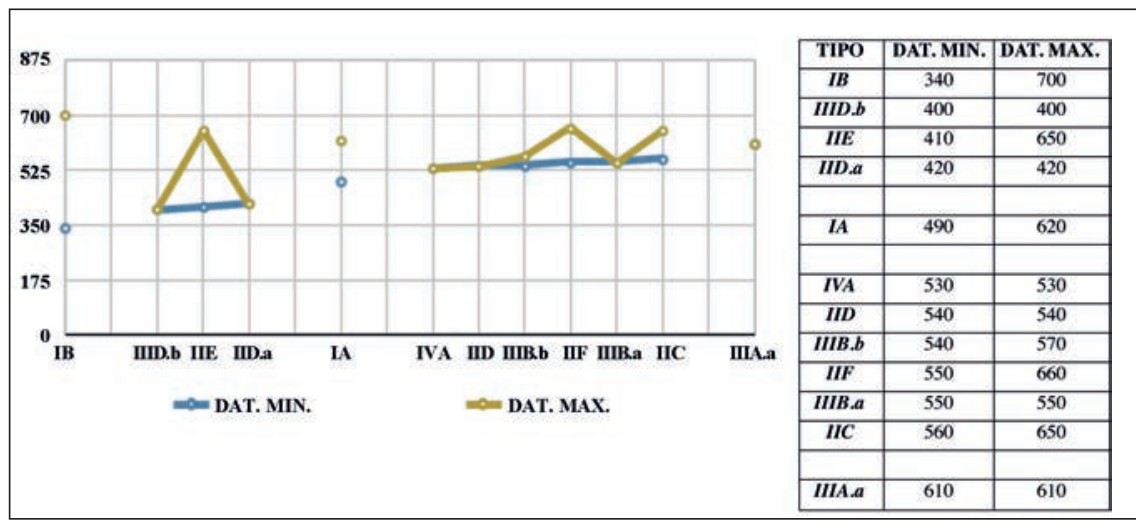

Fig. 9. Dispersión de tipos por fases. 
Fig. 10. Tabla y Gráfico con la perduración de los tipos por fases. Obsérvese en este gráfico cómo el tipo IIE empezando en la fase $2^{\mathrm{a}}$ de nuestra secuencia, perdura hasta la $4^{\text {a }}$. Esto sólo pasa con los tipos genéricos, como el IB y el IA, así como con el que nos ocupa.

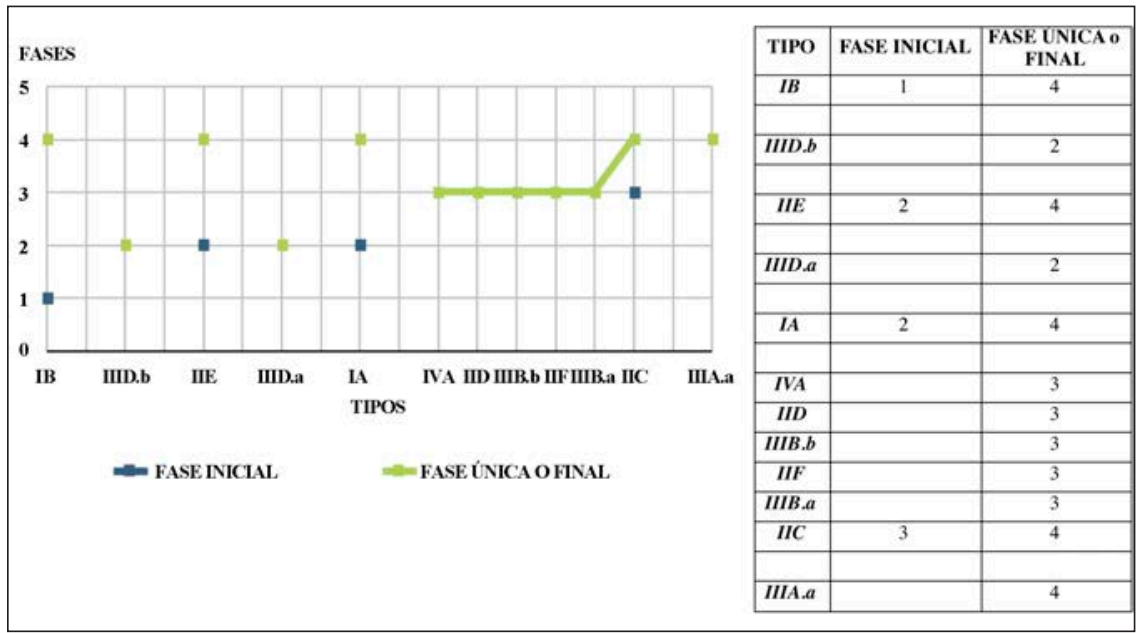

Intentaremos ahora, por lo tanto, ahondar en la información que hemos obtenido y procesado de la excavación para establecer parámetros objetivos pero que aproximen aún más si cabe subtipos a fases cronológicas. Para ello, hemos confeccionado la siguiente tabla y gráfico (fig. 10).

En el citado gráfico se observa, con más claridad, que si bien existen dos fases más o menos definidas (la $2^{\mathrm{a}}$, con los subtipos IIIDb, IIIDa; la $3^{\text {a }}$, con los subtipos IVA, IID, IIIBb, IIF, y IIIBa; y la 4 $4^{\text {a }}$, con el subtipo IIIAa), los subtipos IB, IIE, IA y IIC se dan en varias fases. Es cierto que no en todas, así, el IB, como ya hemos dicho, es el único que sí, pero, por ejemplo los subtipos IIE y IA empiezan a partir de la $2^{\text {a }}$ fase, mientras que el IIC sólo aparece a partir de la $3^{\text {a }}$ fase. Estos últimos datos nos dan varias pistas que podemos rastrear.

Para ello, hemos confeccionado ahora la tabla siguiente en donde observamos en qué fases se dan dichos subtipos y su frecuencia (fig. 11).

Por lo tanto, tendríamos una fase $1^{\mathrm{a}}$ con escasos subtipos, para pasar a una fase $2^{\mathrm{a}}$ con dos subtipos propios
(IIIDb y IIIDa), una fase $3^{\text {a }}$ con cuatro subtipos propios (IID, IIIBb, IIF y IVA), y a los que podríamos incorporar al IIC; y una última fase $4^{\mathrm{a}}$ con un subtipo propio (IIIAb), y al que podríamos añadir tanto al IA como al IB, quedando el IIE sin una adscripción clara aún.

\section{DEPÓSITO FUNERARIO Y TIPOS DE TUMBAS EN LA NECRÓPOLIS DEL TOSSAL DE LES BASSES}

Como quiera que en apartados anteriores ya hemos analizado el tipo de tumbas que se han documentado en nuestra necrópolis, así como también su posible adscripción cronológica, toca ahora intentar relacionar dicha información con los depósitos funerarios que existían en dichas tumbas.

En cualquier caso, y antes de ello, es necesario detenernos en el propio depósito funerario con el fin de poder abordar luego el análisis de relación que nos proponemos.

\begin{tabular}{|c|c|c|c|c|c|c|c|c|}
\hline & IB & IIE/IIID.a/IIID.b & IA & IIC & IID/IIIBa/IIIBb/IIICb/IVA & IIIA.a & IIE & Total \\
\hline 1a & 1 & 0 & 0 & 0 & 0 & 0 & 0 & $\mathbf{1}$ \\
\hline 2a & 1 & 2 & 1 & 0 & 0 & 0 & 1 & $\mathbf{5}$ \\
\hline 3a & 2 & 0 & 1 & 2 & 7 & 0 & 0 & $\mathbf{1 2}$ \\
\hline 4a & 4 & 0 & 4 & 1 & 1 & 1 & 1 & $\mathbf{1 2}$ \\
\hline Total & $\mathbf{8}$ & $\mathbf{2}$ & $\mathbf{6}$ & $\mathbf{3}$ & $\mathbf{8}$ & $\mathbf{1}$ & $\mathbf{2}$ & \\
\hline
\end{tabular}

Fig. 11. Frecuencia de aparición de diversos tipos y subtipos por fases. 


\begin{tabular}{|c|c|c|c|c|c|c|}
\hline $\begin{array}{c}\text { AJUAR } \\
\text { SIMBÓLICO }\end{array}$ & cerámica & vidrio & moneda & & TOTAL \\
\hline VESTIMENTA & 12 & 4 & 4 & & & $\mathbf{2 0}$ \\
\hline & 17 & 1 & 1 & 1 & & $\mathbf{2 0}$ \\
\hline $\begin{array}{c}\text { ADORNO } \\
\text { PERSONAL }\end{array}$ & pendientes & $\begin{array}{c}\text { pulseras } \\
\text { brazaletes }\end{array}$ & colgante & anillo sortija & cuentas collar & \\
\hline & 18 & 9 & 9 & 22 & 27 & $\mathbf{8 5}$ \\
\hline OTROS & otros & & & & & \\
\hline & 26 & & & & & $\mathbf{2 6}$ \\
\hline
\end{tabular}

Fig. 12. Tipos de depósitos funerarios documentados en la necrópolis del Tossal de les Basses.

\begin{tabular}{|c|c|c|c|}
\hline $\begin{array}{c}\text { TIPO } \\
\text { TUMBA }\end{array}$ & $\begin{array}{c}\text { CON } \\
\text { DEPÓSITO } \\
\text { FUNERARIO }\end{array}$ & $\begin{array}{c}\text { \% TUMBAS } \\
\text { DEL TIPO }\end{array}$ & $\begin{array}{c}\text { N TUMBAS } \\
\text { DEL TIPO }\end{array}$ \\
\hline 0 & 25 & 20 & 111 \\
\hline IB & 20 & 16 & 90 \\
\hline IA & 17 & 22 & 120 \\
\hline IIE & 14 & 11 & 59 \\
\hline IIC & 10 & 9 & 51 \\
\hline IID & 6 & 3 & 18 \\
\hline IIB & 4 & 3 & 17 \\
\hline IIIBb & 3 & 3 & 17 \\
\hline IIA & 2 & 5 & 30 \\
\hline ID & 1 & 1 & 1 \\
\hline IIF & 1 & 1 & 4 \\
\hline IIG & 1 & 1 & 1 \\
\hline IIIAb & 1 & 1 & 10 \\
\hline IIIDa & 0 & 1 & 2 \\
\hline IIIDb & 1 & 1 & 8 \\
\hline
\end{tabular}

Fig. 13. Relación entre los tipos de tumbas y la presencia de depósitos funerarios.

Empezaremos por decir que, como viene siendo habitual en las necrópolis de esta época en nuestro entorno geográfico, la escasez de depósitos funerarios es la tónica habitual. Así, sólo un $20 \%$ de las tumbas documentadas presenta algún tipo de depósito funerario. Más adelante veremos cómo ese porcentaje variará según las distintas fases de la necrópolis. Este depósito funerario (fig. 12) se distribuye entre:

- Ajuar simbólico (cerámica, vidrio y monedas).

- Vestimenta (hebillas, fíbulas, remache de cinturón, placas de cinturón).

- Adorno personal (pendientes, pulseras/brazaletes, colgantes, anillos/sortijas, cuentas

de collar).

- Otros.

Como hemos comprobado, la mayoría del depósito funerario se relaciona con el adorno personal (56\%) siguiéndole, de lejos y en igual proporción, los elementos de la vestimenta y el ajuar simbólico (con un $13 \%$ respectivamente, y excluyendo al concepto "otros" que reúnen a variados supuestos muy minoritarios). En cuanto a la distribución de dicho porcentaje entre los distintos tipos de ítems que hemos establecido, podemos decir que el depósito funerario mayoritario (dejando aparte el ítem "otros") es el de las cuentas de collar (18\%), seguido muy de cerca por los anillos/ sortijas $(15 \%)$ y pendientes $(12 \%)$. Luego aparecen ya elementos de la vestimenta, como las hebillas (11\%) y simbólicos como las cerámicas $(8 \%)$. Vuelven a aparecer los elementos de adorno personal: los colgantes $(6 \%)$ y las pulseras/brazaletes $(6 \%)$. Les siguen el vidrio (3\%) y las monedas (3\%). Los demás ítems ya son muy reducidos.

Volviendo ahora a los tipos de tumbas y su relación con los depósitos funerarios, podemos empezar diciendo que, a partir de la siguiente tabla, hemos podido sacar una serie de conclusiones de gran interés (fig.13). 


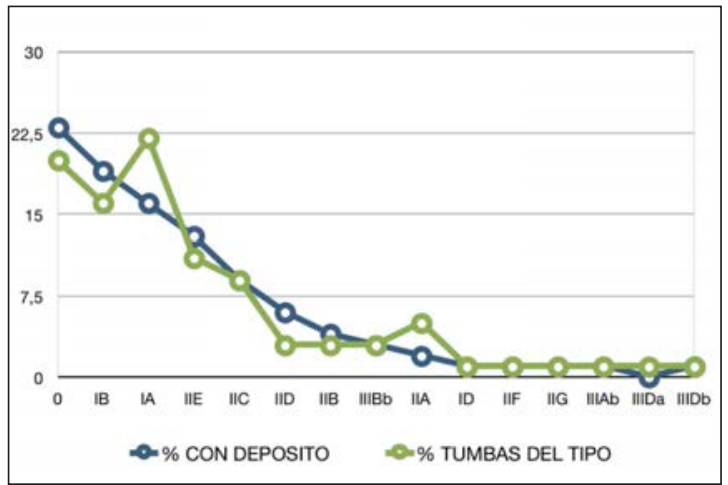

Fig. 14. Comparación entre tipos de tumbas y frecuencia de asociación a depósitos funerarios.

Los primeros datos de interés son los relativos al porcentaje de depósito funerario que aparece por tipo de tumbas. Excluyendo del análisis al tipo 0, aparece con más frecuencia depósito funerario en las tumbas del tipo IB (19\%), seguido de cerca por el tipo IA (16\%), tipo IIE (13\%) y tipo IIC (9\%). Luego están porcentajes intermedios para los tipos IID (6\%) y IIB (4\%), quedando el resto ya en porcentajes mínimos. Como quiera que dichos porcentajes pudieran estar condicionados por el número de tumbas de cada tipo, vamos ahora a comparar estos datos en el gráfico siguiente (fig. 14).

Podemos comprobar cómo, en la mayoría de tipos, los porcentajes -efectivamente- entre número de tumbas y presencia de depósito funerario, es proporcional. Sin embargo, hay algunos casos en donde esto no ocurre. Por ejemplo, el tipo IA presenta una desproporción evidente, siendo menor el número de depósitos funerarios, lo que nos estaría hablando de que, siendo alta su presencia, existe una tendencia para este tipo de disminución de depósitos funerarios. Igual podemos ver que ocurre con el tipo IIA, en donde el porcentaje de depósitos funerarios no coincide con el de tumbas de este tipo. Para el tipo IIIDa debe ocurrir algo parecido.

Otra variable es la que demuestra el gráfico con respecto al tipo IID, existiendo un mayor porcentaje de depósitos funerarios que porcentaje del tipo respecto al total de tumbas. Ello debe significar que se trata de un tipo propicio para utilizar a la hora de proceder a la introducción de algún tipo de depósito funerario. Es posible que estas anomalías tengan algún significado o interpretación ${ }^{4}$.

En cuanto a relación de depósitos funerarios y tipos, se puede decir lo siguiente:

\begin{tabular}{|l|c|c|c|c|}
\hline & Tipo de tumba & Adorno & Vestimenta & Simbólico \\
\hline FASE 2 $^{\mathbf{a}}$ & IIIDb & 100 & 0 & 0 \\
\hline FASE 3 $^{\mathbf{a}}$ & IID & 100 & 0 & 0 \\
\hline & IIIBb & 25 & 50 & 25 \\
\hline & IIF & 0 & 100 & 0 \\
\hline & IIC & 62 & 15 & 23 \\
\hline FASE 4 & IA & 45 & 23 & 32 \\
\hline & IB & 64 & 24 & 12 \\
\hline & IIE & 78 & 11 & 11 \\
\hline
\end{tabular}

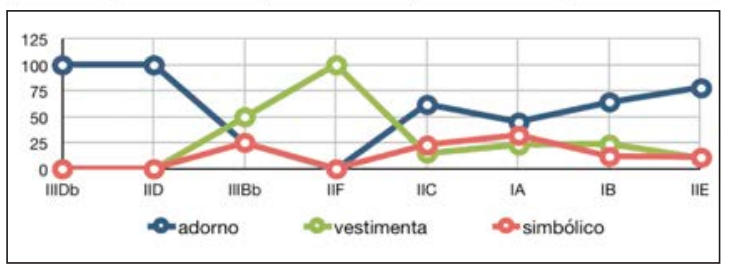

Fig. 15. Evolución del tipo de depósito en relación al tipo de tumba y la fase cronológica.

A. Existen variaciones cualitativas y cuantitativas entre los distintos tipos de tumbas a la hora de disponer o no de depósito funerario.

B. Esa misma variedad se da respecto a qué elementos del depósito funerario se refiera, esto es, ajuar simbólico, adorno personal o vestimenta.

C. Esta variación puede tener una causa cronológica $\mathrm{y}$, por lo tanto, cultural.

Efectivamente, creemos poder avanzar una hipótesis sobre la posibilidad de que dichas variaciones se deban al momento cultural al que pertenezca cada tipo en la necrópolis. A saber, y si vemos la tabla y gráfico de la figura 15 , en donde hemos relacionado los tipos que más atrás hemos propuesto como genuinos y posibles de cada una de las etapas que proponemos para la necrópolis (no hablamos de la fase 1a por no tener un tipo de tumba claro), podremos observar algunos hechos relevantes:

- La fase $2^{\text {a }}$ se caracteriza por una escasez importante de elementos del depósito funerario, y cuando lo hay sólo son elementos de adorno personal.

- Por su parte, la fase $3^{\mathrm{a}}$ se caracterizará por un descenso gradual e importante de los elementos de adorno, si bien vuelven a aparecer al final del periodo.

- Destaca, igualmente, para la fase $3^{\text {a }}$ la aparición, escasa pero relevante por su significación, de elementos del ajuar simbólico (recipientes de vidrio).

- En cualquier caso, lo que más se da en esta fase $3^{\text {a }}$ son los elementos relacionados con la vestimenta.

- La fase $4^{\text {a }}$ se caracteriza por la existencia en las tumbas de todos los elementos del depósito funerario, 


\begin{tabular}{|l|c|c|c|}
\hline & FASE 2 & FASE 3 & FASE 4 \\
\hline cerámica & & & 5 \\
\hline vidrio & & 1 & 3 \\
\hline pendientes & & 1 & 5 \\
\hline pulsera/brazalete & & & 3 \\
\hline colgante & & 1 & 3 \\
\hline anillo/sortija & & & 5 \\
\hline hebilla & & 2 & 6 \\
\hline fíbula & & & \\
\hline remache cinturón & & & 1 \\
\hline placa cinturón & & & 1 \\
\hline cuentas collar & 1 & 3 & 8 \\
\hline moneda & & & 1 \\
\hline otros & & 4 & 6 \\
\hline
\end{tabular}

Fig. 16. Evolución por fases de los elementos del depósito funerario.

en porcentajes más o menos igualitarios, aunque siempre por encima los elementos de adorno personal.

- Otra característica de la fase $4^{\mathrm{a}}$ será la presencia de vasijas de cerámica como elementos del ajuar simbólico.

- Por último, es significativo subrayar cómo el tipo IIC, a caballo entre las fases $3^{\mathrm{a}}$ y $4^{\mathrm{a}}$, demuestra estar más relacionado con la $4^{\mathrm{a}}$.

Todo lo expuesto podría concretarse con la siguiente tabla (fig. 16), en donde se aprecia, a simple vista, cómo evoluciona el depósito funerario según las fases cronológicas propuestas. Destaca, por ejemplo, el hecho de que en el cuarto periodo (el que mayor variedad de elementos presenta, y en una proporción similar), la existencia de recipientes de cerámica podría considerarse como "fósil director" del mismo.

\section{CRONOLOGÍA DE LOS DEPÓSITOS FUNERA- RIOS Y FASES DEFINITIVAS DE LA NECRÓPOLIS DEL TOSSAL DE LES BASSES}

Intentar concretar una cronología para la necrópolis tardo-antigua del Tossal de les Basses, después de toda la información que hemos analizado, no parece una tarea complicada. No podemos decir lo mismo de la interpretación que de dichos datos y fechas podamos ir haciendo en un panorama -el tardo-antiguo- ya de por sí complicado en nuestras tierras.
Toca ahora proponer una cronología de la ocupación de la necrópolis. Hemos podido comprobar más arriba la existencia de algunas de las piezas más significativas del depósito funerario, fundamentalmente piezas cerámicas y hebillas de cinturón. Teniendo en cuenta que, en algunos casos vienen acompañadas de dataciones absolutas de los enterramientos, se ha podido incluso ajustar aún más esa cronología que, en términos generales, viene a ceñirse a los parámetros normalmente establecidos en la bibliografía científica sobre el tema.

Quizá el clásico de obligada referencia al que dirigirse para hacer comparaciones sea la necrópolis visigoda de El Carpio del Tajo (Toledo), magistralmente estudiada por Ripoll (1985). En 1990 realizó una ampliación de la información que es la que ahora, básicamente, comentaremos (Ripoll 1990). Así, estableció cuatro niveles diferentes para todo el período de ocupación visigoda e hispano-visigoda.

- Los niveles propiamente visigodos serían los que denominó II y III, que abarcan desde finales del s. V hasta principios del s. VI d.C., el primero, y desde principios del s. VI a mediados de la $2^{\text {a }} 1 / 2$ del s. VI el segundo.

- Los niveles IV y V, corresponderían a las producciones latino-mediterráneas y bizantinas de finales del s. VI hasta principios del s. VIII.

Como quiera que, en cualquier caso, dicha necrópolis se sitúa en una zona (Toledo) distinta a la nuestra en cuanto a evolución histórica, es igualmente necesario buscar referencias complementarias algo más cercanas geográficamente y con una evolución histórica más coincidente con la de las tierras alicantinas. Es por ello que es obligado mirar a las importantes necrópolis andaluzas y murcianas, sobre todo de Cartagena y sus alrededores que compartieron la influencia -por ejemplo- de la ocupación imperial bizantina ${ }^{5}$. Compararemos ahora nuestra necrópolis con estos datos. Hay que recordar que ya habíamos planteado más arriba una propuesta cronológica para las cubiertas de las tumbas y construcciones interiores de éstas, a partir de varias fases constructivas que ahora hay que cuadrar con el registro material y las dataciones absolutas.

\section{PRIMERA ETAPA (1/2 s. IV d.C. $)^{6}$}

\section{CAUSAS:}

Se trata de la génesis del cementerio que, con el tiempo, se irá desarrollando. Por sus fechas, y por la carencia de elementos que puedan adscribirse a la religión cristiana, 


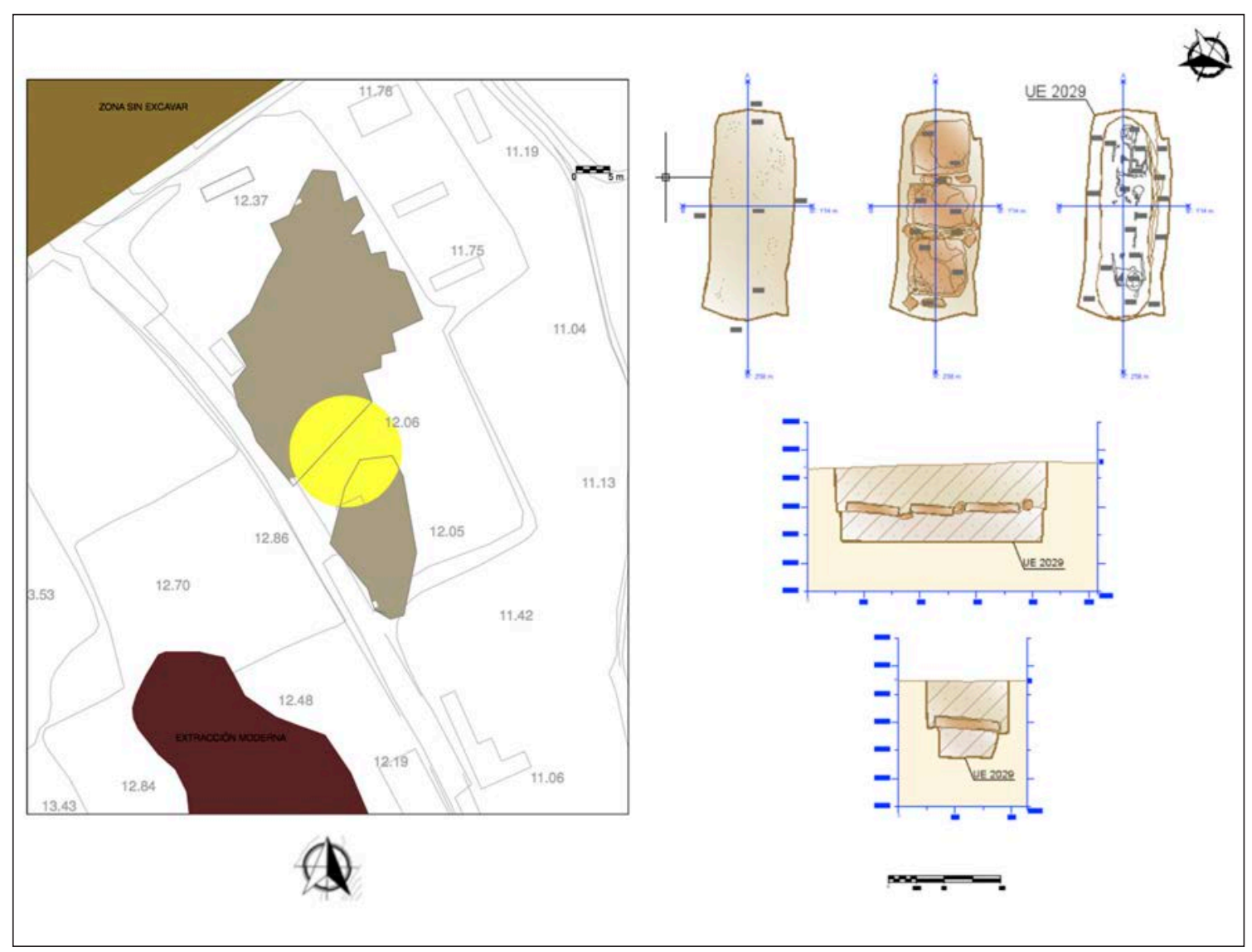

Fig. 17. Localización dela primera etapa de la necrópolis y representación de una tumba tipo IB, con cubierta de lajas de piedra, que apoya sobre un banco lateral o pre-fosa.

pensamos que incluso no tendría porqué relacionarse con el cristianismo como ocurre, por ejemplo en Valencia, con manifestaciones paganas para estos momentos. La causa de su origen debería relacionarse con las instalaciones agropecuarias cercanas (villa de los Sectores 4 y 7, fundamentalmente).

\section{CRONOLOGÍA Y TIPOS CONSTRUCTIVOS:}

Fechada, en base a cronologías absolutas, a mediados del s. IV d.C., está representada, fundamentalmente, por el tipo IB (cubierta de lajas de piedra sobre banco lateral), que perdurará mucho en el tiempo por ser, quizá, uno de los más simples. Efectivamente, algunas tumbas de este tipo se han datado una cronología temprana: la tumba 493 (cal. 340 d.C.), mientras que otras llegan a época visigoda o, incluso, pudieran ser de época islámica.

\section{EXTENSIÓN:}

Su extensión, respecto al área cementerial, nos es desconocida como quiera que sólo disponemos de una tumba con datación absoluta. En cualquier caso, cabría la posibilidad de que la posición centrada de la tumba TB493 (ver plano en fig. 17) apunte al lugar de origen de la necrópolis, punto a partir del cual se expandiera. Sin embargo, nada podemos asegurar por falta de datos en un sentido o en otro.

\section{REGISTRO MATERIAL:}

Como quiera que el depósito funerario que conserva este tipo en este período cronológico es nulo ${ }^{7}$, es poco lo que podemos aportar de esta fase en cuanto a su registro material.

\section{FINALIZACIÓN DEL USO:}

No sabemos en qué momento pudo dejar de usarse la necrópolis con esas características. Aunque está aún por 
estudiar más exhaustivamente, y teniendo claro que debió tener una relación clara con lo acontecido en las villas de su entorno más inmediato, no podemos descartar la existencia de algún tipo de convulsión en el contexto de los cambios producidos por la caída del Imperio romano y las incursiones bárbaras a la península (por ejemplo, la toma de Cartagena y Sevilla hacia el 411 d.C., contada en Hydat. 21; 86).

La documentación en la villa del Sector 7 de una ocultación monetal podría apuntar por ahí. Los niveles anteriores a los de la ocultación documentan TSCD, más concretamente un plato Lamboglia 53 bis (Hayes 61B) y un cuenco Hayes 91B. Estas producciones africanas se fabrican entre el 380 d.C. y el 500 d.C., por lo que la ocultación podría haberse dado entre finales del IV y todo el s. V.

Ahora bien, que dicha ocultación tenga un origen basado exclusivamente en el simple acaparamiento por falta de numerario o cambio de moneda, o es debido a las convulsiones comentadas (Ripollès 1980), hoy por hoy es muy difícil de determinar. Ocultaciones monetarias se han estudiado, por ejemplo, para Alicante (González Prats y Abascal 1987) y para la próxima la Región de Murcia (Lechuga 1985). En concreto, y por contexto arqueológico similar (por la aparición de TSCD con las formas atestiguadas en nuestro yacimiento), tendríamos el conjunto de monedas hallado en el Cerro de la Ermita de Singla (Caravaca) (Lechuga 1985, 204 ss.), en donde además se documenta una villa agrícola y enterramientos, como en nuestro caso.

SEGUNDAETAPA (mediados/finales s. V-inicios s. VI d.C.)

\section{CAUSAS:}

Sabemos que en el área de nuestro cementerio se documentan ahora elementos de un posible culto religioso (por ejemplo, el faldín e inicios de las piernas de una tosca escultura: ¿moscóforo?). Tendríamos, quizá, algún tipo de espacio cultual, que pudo ser el origen, o mejor, consolidación y desarrollo de la importante necrópolis, lo cual viene a coincidir prácticamente con la fecha de la erección de la Basílica de Ilici y su cementerio.

\section{CRONOLOGÍA Y TIPOS CONSTRUCTIVOS:}

Avalando estas fechas, también tendríamos en el Tossal de les Basses una inscripción claramente cristiana realizada en piedra arenisca, en donde se lee: RECESSIT IN PACE IESTEFANAE dXVII CAL IANUARIAS, que se fecha por lo tanto en el año 479 d.C., y que nos deja claro que para ese momento ya había cristianos en Alicante y que, al menos, se enterraban en esta zona.
Podría corresponderse, salvándose las distancias del contexto geográfico, con el nivel II de Ripoll que estableció para la necrópolis del Carpio de Tajo. Del mismo modo, se podría paralelizar con el nivel II establecido para Cartagena.

En este momento se produce por lo tanto una nueva necrópolis, o un crecimiento de la anterior. en tipologías constructivas, aunque relativamente, como ahora veremos. Podemos asignar unos tipos claros a esta época (IIID.b, IIIDa), si bien algunas tumbas del tipo IIE también deberían adscribirse a este momento, porque así lo demuestra alguna datación absoluta.

Por cronologías absolutas estaríamos desde mediados del s. V a inicios del s. VI d.C. Tienen los tres tipos un denominador común que les hacen, prácticamente, iguales, esto es: el presentar túmulo de piedras por encima de lajas de piedra, variando sólo en cuanto a si tienes cista o no, o banco lateral. Por lo tanto, habría que pensar que el "fósil director" de este periodo es el complemento túmulo sobre laja de piedras. Además. la mayoría de estos tipos no presentan perduración en el tiempo, sólo el tipo IIE sobrepasa los doscientos años.

\section{EXTENSIÓN:}

Como puede apreciarse en el plano correspondiente a esta fase (fig. 18), su área de expansión ahora puede determinarse, aproximadamente, así como la existencia de calles en el cementerio.

\section{REGISTRO MATERIAL:}

Este segundo periodo está dominado por los elementos de adorno, aunque sólo con la presencia de las cuentas de collar.

\section{FINALIZACIÓN DEL USO:}

Aunque podríamos pensar que su finalización se produce con la llegada de una etapa que viene a coincidir con la ocupación bizantina, creemos poder atisbar la existencia de una transición entre la etapa que nos ocupa y aquella.

ETAPA DE TRANSICIÓN 2/3 (inicios del S. VI a mediados del s. VI d.C.):

\section{CAUSA:}

Como ya hemos apuntado más arriba, si bien podríamos englobarla en la $3^{\mathrm{a}}$ etapa, pensamos que podría existir una subetapa o una etapa de transición, previa a la llegada de aquella. 


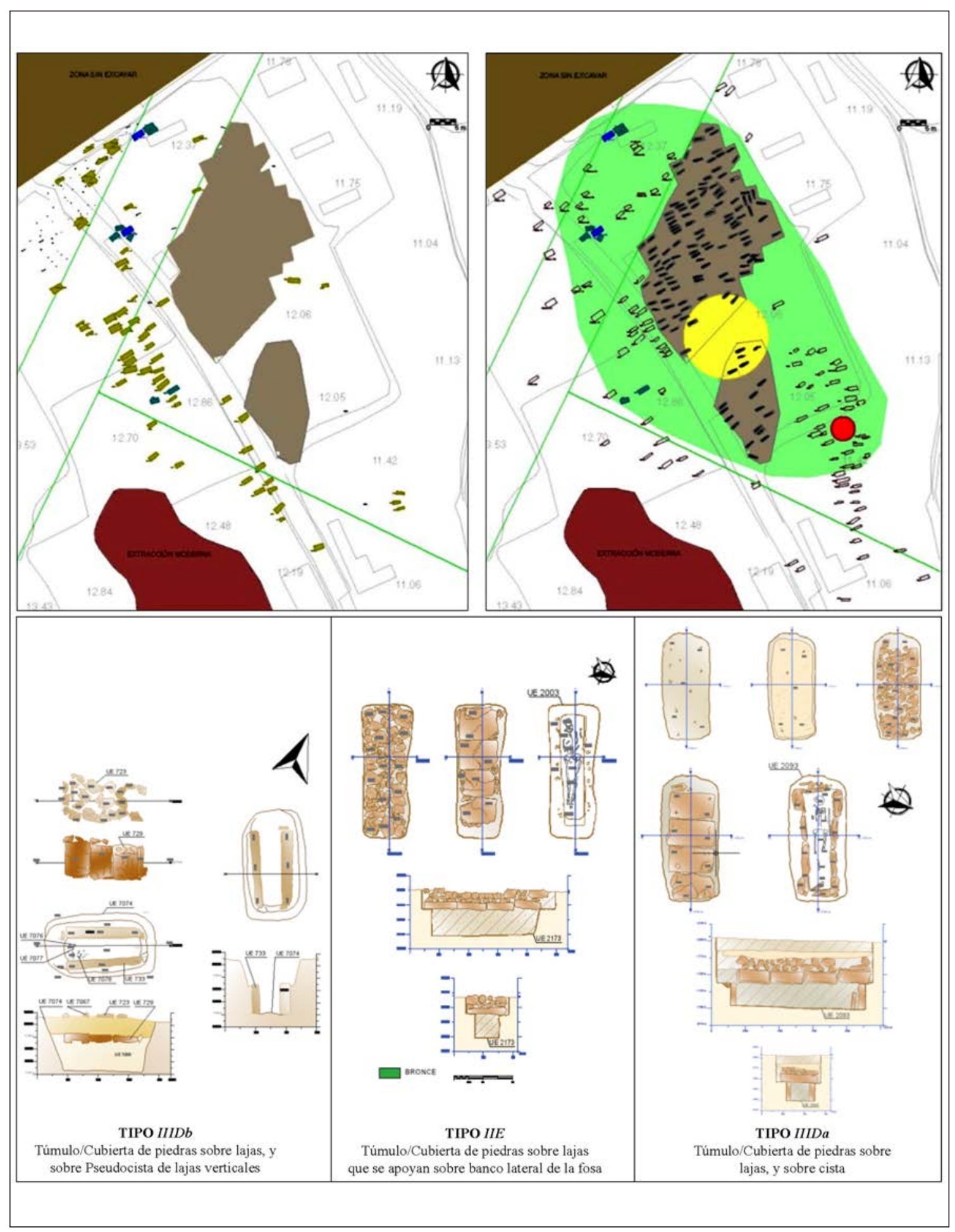

Fig. 18. Segunda etapa de la necrópolis. 


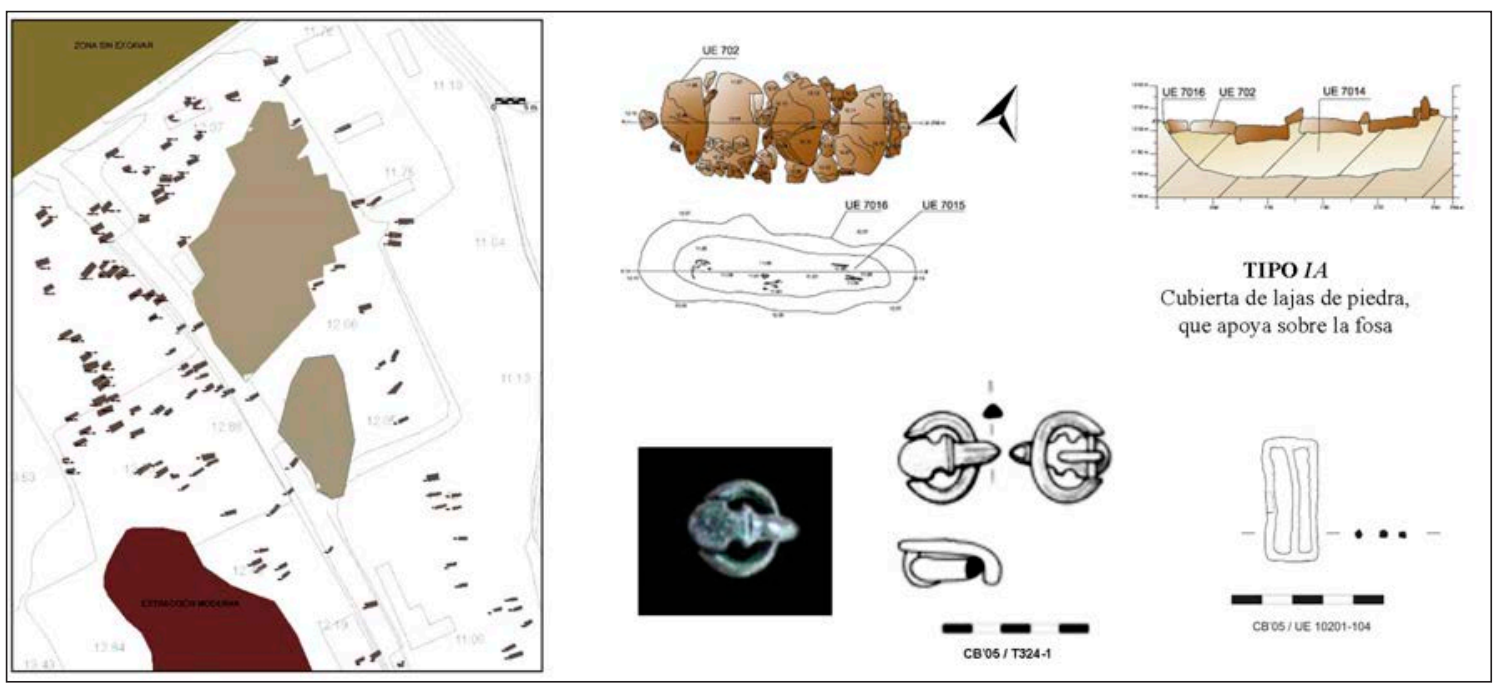

Fig. 19. Etapa de transición de la necrópolis.

\section{CRONOLOGÍA Y TIPOS CONSTRUCTIVOS:}

Para este momento sólo hemos podido constatar, por dataciones absolutas, el inicio del uso del tipo IA que, al igual que pasaba con el IB, se prolonga mucho en el tiempo, por su sencillez constructiva (cubierta de lajas sobre fosa). Se fechan sus inicios a principios del s. VId.C., por lo que podría corresponderse, salvándose las distancias del contexto geográfico, con el nivel III de Ripoll que estableció para la necrópolis del Carpio de Tajo (525-560 d.C.). Del mismo modo, se podría paralelizar con el nivel III establecido para Cartagena, que llega al 560-580 d.C.

\section{EXTENSIÓN:}

Es bastante difícil establecer un área concreta toda vez que no disponemos, con certeza, de tumbas definitivas para este momento. Sabemos que, al menos, algunas de las del tipo IA se pueden circunscribir a este momento. Por depósito funerario quizá también de los tipos IIC, IIE, y IIF, pero nos falta información para ajustar límites espaciales. En cualquier caso, conociendo el espacio de las fases inmediatamente anteriores y posteriores a la que nos ocupa, nos inclinamos a pensar que sería prácticamente la misma que en ellas.

\section{REGISTRO MATERIAL:}

El depósito funerario de las tumbas que podríamos fechar en esta etapa se circunscribe a hebillas de cinturón ovaladas. Por ejemplo las que tienen aguja de base escutiforme. Estas hebillas evolucionan desde tipos tardorromanos, y se encuadran en el citado nivel III de Ripoll (Gutiérrez 1990). Con el mismo encuadre cronológico tendríamos a las hebillas rectangulares, que son una evolución de las hebillas ovaladas con hebijón escutiforme.

\section{FINALIZACIÓN DEL USO:}

Parece claro que podemos enmarcar la terminación de esta etapa con la llegada del influjo bizantino a nuestras tierras a mediados/finales del s. VI d.C.

TERCERA ETAPA (entre $c a .550$ y 570 d.C.)

\section{CAUSA:}

Este período se inicia con la existencia de una zona de enterramientos al $\mathrm{O}$ de la que nos ocupa, junto a la villa romana de Las Torres que se caracteriza -al menos por lo que sabemos- por una tipología constructiva de sus tumbas a base exclusivamente de tegulae o ladrillos grandes a doble vertiente o planas (tipo IVA), con paralelos en los cercanos yacimientos de Port Tossal y los Antigones (actual barrio de Benalúa). Sin embargo, un escaso número de tumbas de la necrópolis del Tossal de les Basses adoptarán el tipo IVA. Una posible explicación de esa escasa presencia de tumbas del Tipo IVA en nuestra necrópolis, siendo únicas en la cercana villa de Las Torres, sea el carácter alóctono de sus ocupantes (¿milites?), que no ocuparon el mismo espacio sacro que habían tenido los ahora ocupados. 


\section{CRONOLOGÍA Y TIPOS CONSTRUCTIVOS:}

Creemos poder adscribir esta etapa de la necrópolis a un momento inmediatamente posterior al 550 d.C. Podría corresponderse, salvándose las distancias del contexto geográfico, con el nivel IV de Ripoll que estableció para la necrópolis del Carpio de Tajo. Del mismo modo, se podría paralelizar con el nivel IV establecido para Cartagena (560-580-600/40 d.C.)

Como ya avanzamos en 1994, prácticamente a la par que se produce la ocupación de la costa sureste peninsular por los Bizantinos a mediados del siglo VI d.C. (552 d.C.), se experimentará una disminución progresiva de población en la zona de la Albufereta (Rosser 1994: 101) circunstancia que, si nuestra hipótesis de distribución de tumbas por etapas y subfases en acertada, se corrobora ahora. Efectivamente, el número de tumbas, y por lo tanto su incidencia en la necrópolis y el territorio circundante a ésta no parece haya sido importante.

\section{EXTENSIÓN:}

Por la información de que disponemos, la presencia de esta etapa en la necrópolis es muy escasa (hay que tener en cuenta que, como ya hemos dicho, se documentaron un número importante de tumbas de este momento en la necrópolis de las Torres, junto a la villa del mismo nombre), por lo que, prácticamente no tiene incidencia en la evolución de la extensión de la zona cementerial.

\section{REGISTRO MATERIAL:}

Teniendo en cuenta la escasa representación del tipo IVA en la necrópolis es difícil poder adscribir un registro material concreto a esta etapa. Sí se documentó interesante registro material en la citada necrópolis de las Torres (Rosser 1992-1993).

\section{FINALIZACIÓN DEL USO:}

Parece claro relacionar la finalización de esta fase con la llegada de otro tipo de influencias a estas tierras, momento al que habría que adscribir la fase siguiente.

\section{CUARTA ETAPA (desde ca. 570 d.C. hasta 1/2 s. VII)}

\section{CAUSA:}

La etapa anterior termina con la constatación de nuevas influencias culturales en nuestras tierras, momento al que hay que circunscribir esta 4 a etapa. En un momento que fechamos en $c a .570$ d.C., se producen una serie de cambios tanto en la tipología constructiva

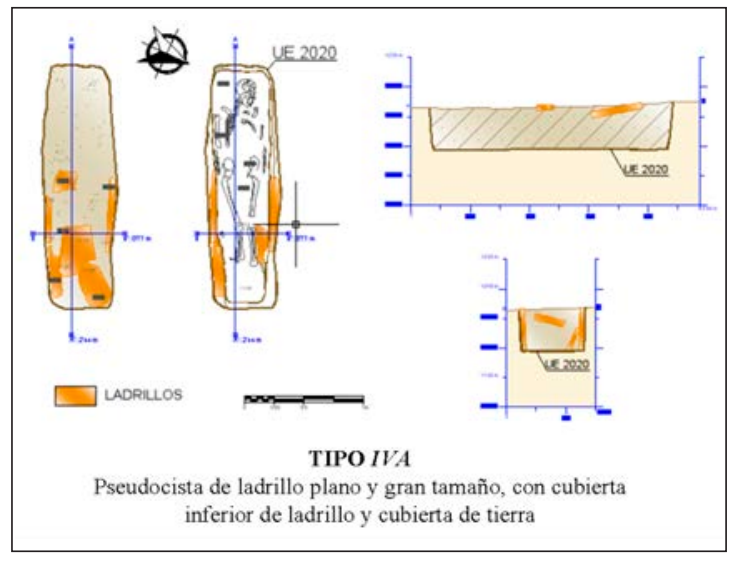

Fig. 20. Tercera etapa, de influencia bizantina.

de las tumbas como en el registro material que conforma el depósito funerario, respecto a la etapa anterior. Llamaremos a este momento $1^{\text {a }}$ fase. A partir de la $1^{\text {a }} 1 / 2$ del s. VII d.C. llegará la que hemos llamado $2^{\text {a }}$ fase de esta etapa.

\section{CRONOLOGÍA Y TIPOS CONSTRUCTIVOS:}

Podría corresponderse, salvándose las distancias del contexto geográfico, con el nivel V de Ripoll que estableció para la necrópolis del Carpio de Tajo. Del mismo modo, se podría paralelizar con el nivel $\mathrm{V}$ establecido para Cartagena (600/40-710/20 d.C.)

Como hemos comentado más arriba, los tipos constructivos de las tumbas cambian, dejando de lado el uso del ladrillo (tipo IVA). Se produce en la 1a fase una mayor variedad de tipos (IID, IIF, IIIB.a, IIIB.b, IIIC.b, IIC), pudiendo también existir tumbas en este periodo de los tipos IA y IB.

Se podría pensar que estamos ante una serie de personas enterradas y -por ende- de familiares que los entierran, distintas, con otras tradiciones culturales que reflejan en sus maneras de enterrar, y con mayor exigencia a la hora de elegir el tipo de tumba para el fallecido. Se encuadran desde ca. 570 hasta principios del VII d.C. La perdurabilidad de los tipos es muy escasa (sólo el tipo IIF llega a los cien años de uso), y se circunscribe a esta etapa, lo que -al igual que ocurría con la $2^{\mathrm{a}}$ etapaexiste una gran coherencia en la conformación de la misma. Alguno de esos nuevos tipos, en cualquier caso, siguen la tradición de la etapa $2^{\text {a }}$ en cuanto al uso de cubiertas de túmulo sobre losas de piedra, aunque con ligeras variaciones (tipo IID, IIF y IIC). Otras tumbas 


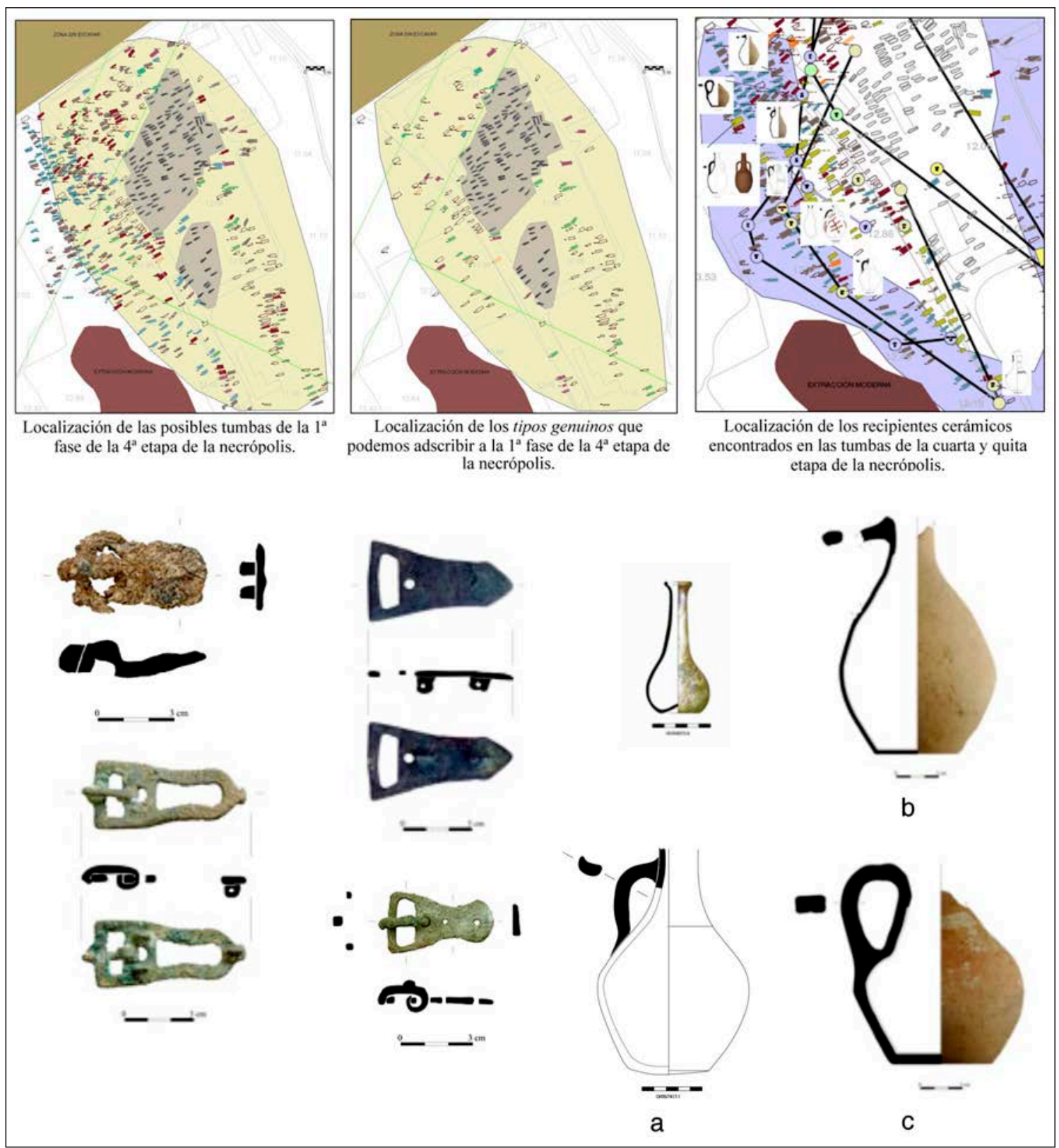

Fig. 21. Cuarta etapa: hispanovisigoda.

mantendrán el túmulo, pero eliminando la cubierta inferior de lajas (tipo IIICb). Sin embargo, en seguida aparecen nuevos tipos en donde ya ha desaparecido el túmulo (tipos IIIBa, IIIBb). Quizá el elemento novedoso, y denominador común de la mayoría de esos tipos y, por lo tanto, "fósil director" de esta $4^{\text {a }}$ etapa de la necrópolis sea las cistas, sobre todo verticales. Aparecen en, al menos, tres de los siete tipos documentados, pudiendo unir un cuarto tipo si considerásemos a los ladrillos verticales del tipo IVA como "cista” y, quizá, su precedente y al que imitan. Subrayaremos, por último, la aparición sobre una tumba (TB 352) del citado tipo IIC, de un claro signaculum con cruz griega incisa sobre la piedra. 
Es ahora cuando, parece, pudo destruirse un edificio cultual, o al menos se remodeló profundamente. En tal sentido apunta, no sólo, la reutilización de piezas en cubiertas de tumbas de esta etapa, sino la fecha de muchas de éstas.

Dicha necrópolis se prolongará en el tiempo ( $2^{\mathrm{a}}$ fase de esta $4^{\mathrm{a}}$ etapa). Por dataciones absolutas sabemos que, por ejemplo, un nuevo tipo constructivo, el IIIAa, se fecharían en los inicios del s. VII d.C. Ello no significa que no se dieran otros tipos. Bien al contrario, para este momento avanzado de la etapa $4^{\text {a }}$ sabemos que existen tumbas -por el depósito funerario que contienen- de los tipos IA, IB, IIE y IIC.

\section{EXTENSIÓN:}

Parece quedar bastante claro, por la distribución tanto de tipos como, sobre todo, de registro material (recipientes de vidrio y cerámica, así como hebillas y broches de cinturón) que en la $1^{\text {a }}$ fase de esta $4^{\mathrm{a}}$ etapa se van completando los espacios en torno al área cementerial ya existente en la etapa anterior. Es decir, que se producen enterramientos sobre todo en los lados mayores al $\mathrm{O}$ y E de la necrópolis, si bien es cierto que se reutilizan algunas tumbas del interior del cementerio. Aparece, por lo tanto, un cementerio bastante mejor estructurado espacialmente.

\section{REGISTRO MATERIAL:}

Los depósitos funerarios son, normalmente, inexistentes o escasos. En cualquier caso, esta etapa se caracterizará, sobre todo en su $1^{\text {a }}$ fase (entre finales s. VI y principios del s. VII d.C.), por un descenso gradual e importante de los elementos de adorno, si bien vuelven a aparecer al final del periodo. Destaca, igualmente, la aparición, escasa pero relevante por su significación, de ciertos elementos del ajuar simbólico. En primer lugar, un ungüentario de vidrio tipo Isings 101, que si bien se fecha en el s. IV, es frecuente encontrar los ejemplares más o menos deformes y con boca descentrada, como es nuestro caso, en enterramientos merovingios y visigodos (Mezquíriz 2003, 148).

Del mismo modo, el ajuar simbólico se ve ahora representado por la presencia de vasijas de cerámica. La datación absoluta de los esqueletos a los que acompaña (ca. 560 d.C.), fue una de las primeras razones que nos hicieron pensar en que debíamos establecer esta etapa en este momento. En primer lugar, tendríamos el Jarro (7417-1), piriforme con asa, de base ligeramente convexa de cerámica común a torno (fig. 21.a). Pasta sobrecocida, con superficie de color rojo y gris; desgrasante calcáreo visible en superficie. Le falta el borde. Pertenece a la TB 315 (del tipo constructivo IIC: túmulo/cubierta de piedras bajo el que se encuentran lajas de piedra). La cronología de la pieza citada coincide, grosso modo, con las dataciones obtenidas por los análisis de C14 para el esqueleto de $c a .560$ d.C. Paraleliza con el tipo 1 de la necrópolis de El Ruedo (Carmona 1991: 372, lám. 2), así como con el tipo Izquierdo 16B. Se ha documentado en la segunda fase de la necrópolis de l'Almoina (Valencia) o en El Pelao (Jorquera, Albacete) (Pascual et al. 2003: 83).

También tendríamos la Botella (2114.1) de base plana, cuerpo bitroncocónico, borde sin diferenciar, cuello hiperbólico y asa cuadrangular que sale del borde (fig. 21.b). Tipo 1 de la necrópolis de El Ruedo (Carmona 1991: 372, Lám. 2) y tipo Izquierdo 16B. Se documentó en la segunda fase de la necrópolis de l'Almoina o en El Pelao (Jorquera, Albacete) (Pascual et al. 2003: 83). Pertenece a la TB 2114, tipo IA (Cubierta de lajas de piedras, que apoya sobre la fosa). El inicio de este tipo se enmarca en una fase intermedia entre la $2^{\mathrm{a}}$ y la $3^{\mathrm{a}}$ de nuestra secuencia, esto es, a finales del s. V d.C., si bien perdurará hasta la $1^{\text {a }} 1 / 2$ del s. VII d.C., momento en el que puede enmarcarse esta tumba por su botella. Hemos encontrado un paralelo para esta vasija, y para la anterior, de nuestra necrópolis en el enterramiento $\mathrm{n}^{\circ} 8$ de la ya citada necrópolis de Peñarrubia (Málaga). Corresponde, como el nuestro, a la forma 16 B de la tipología de Izquierdo (Serrano Ramos et al. 1989-1990: 144. lám. III, n 7). La cronología para esta necrópolis y la datación absoluta de una de las tumbas de nuestro yacimiento (ca. 560 d.C.) vienen a coincidir.

Otra vasija documentada en esta fase de nuestra necrópolis será la Botella (2062.1) de base plana, cuerpo bitroncocónico, borde recto saliente y asa que sale del borde de sección ovalada (fig. 21.c). Pertenece a la TB 2062, tipo IIC (túmulo/cubierta de piedras bajo el que se encuentran lajas de piedra). La cronología de la pieza citada coincide, grosso modo, con las dataciones obtenidas por los análisis de C14 para esta fase.

En cualquier caso, lo que más se da en esta primera fase de esta $4^{\text {a }}$ etapa son los elementos relacionados con la vestimenta. Como apuntó Ripoll, se implantarán ahora nuevas modas procedentes del Mediterráneo que se verán favorecidas por la creación de Hispania bizantina. Ello dio lugar, además, a la existencia de matrimonios mixtos 


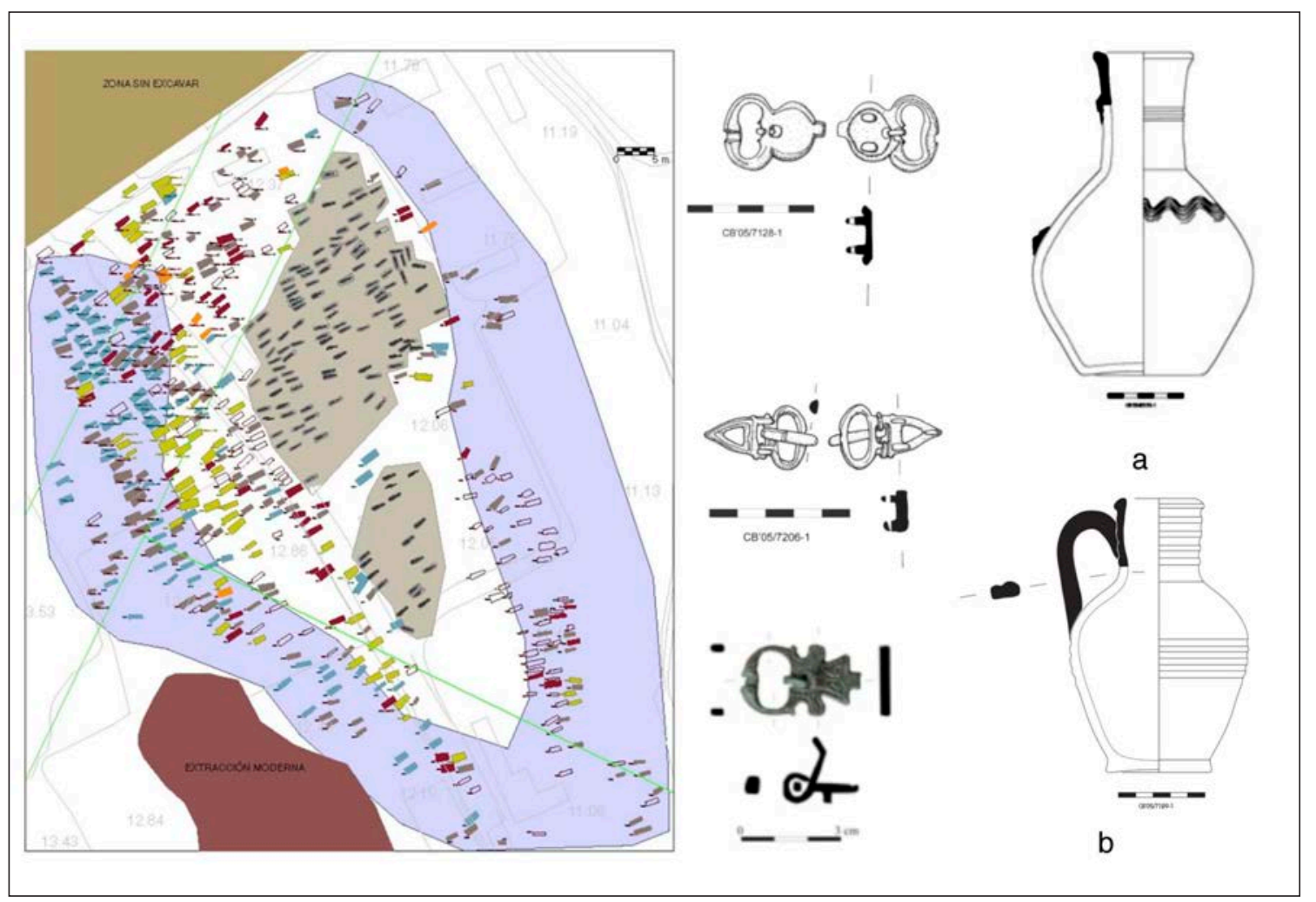

Fig. 22. Segunda etapa visigoda de la necrópolis.

que produjo cambios en la indumentaria y, por ende, en los elementos que lo sustentan: las hebillas de cinturón de placa rígida rectangular y lengüeta de perfiles estrangulados. Se trata, por lo tanto de piezas de tradición latino-mediterránea, evolución de los tipos tardorromanos, y que se corresponden con el citado nivel IV de Ripoll (Gutiérrez 1990).

Por su parte, en una $2^{\mathrm{a}}$ fase de esta $4^{\mathrm{a}}$ etapa, se documentan en las tumbas todos los elementos del depósito funerario, en porcentajes más o menos igualitarios, aunque siempre por encima los elementos de adorno personal. Otra característica, ya documentada en la primera fase de esta $4^{\text {a }}$ etapa, será la presencia de vasijas de cerámica como elementos del ajuar simbólico.

En primer lugar, documentamos el Jarro (2335-1) de borde recto y labio diferenciado, con cuello cilíndrico, cuerpo piriforme y base plana de cerámica común a torno, con pasta granulosa de color beige (fig. 22.a). Presenta una decoración exterior incisa de banda de ondas a peine en el hombro entre finas acanaladuras. La tonalidad exterior es beige grisácea por cocción irregular. El desgrasante calcáreo es visible en superficie. Pertenece a la TB 338 (del tipo constructivo IIC: túmulo/ cubierta de piedras bajo el que se encuentran lajas de piedra). La cronología de la pieza citada coincide, grosso modo, con las dataciones obtenidas por los análisis de C14 para el esqueleto de $c a .590$ d.C. Es semejante a otra de las jarras del Tossal de les Basses, es el tipo 3C1 de la necrópolis de El Ruedo, Izquierdo 11. Allí constituye el tipo más abundante en los ajuares y se fecha en la primera mitad del s. VII (Carmona 1998: 147, lám. 27). Aunque este paralelo se encuentra alejado geográficamente, observamos como curiosamente, en l'Almoina de Valencia, encuentran también en la misma necrópolis cordobesa paralelos para sus piezas (Pascual et al. 2003: 83).

En segundo lugar, estaría la Jarrita (7129-1) de pasta anaranjada, a torno, con el pie indicado, borde recto engrosado exterior y con un tratamiento superficial amarillento muy perdido (fig. 22.b). Posee un cuerpo globular 
y un cuello cilíndrico, y presenta como característica más destacable unas acusadas marcas de torno en cuello y panza. Pertenece al tipo 62 de Bonifay cuya producción experimenta cambios morfológicos desde finales del IV a finales del VII. Se documenta en las Fases 9 y 10 del Teatro de Cartagena (s. VI y el primer cuarto del VII; en el relleno de un pozo bizantino) (Murcia et al. 2003: 182, Fig. 7, 59) asimilable a la forma 4 de Carthago. En concreto, nuestra jarra se asemeja a los ejemplares datados en el siglo VII (Bonifay 2004: 293, Fig. 162). El paralelo más cercano geográficamente lo hallamos en La Alcudia de Elche, y fue recogido por Reynolds en su estudio sobre las cerámicas tardías del valle del Vinalopó constituyendo la forma 12A. A diferencia de nuestra jarra, el ejemplar de Ilici lleva en el cuello las letras MA pintadas en rojo (Reynolds 1993: 141, pl. 60, 1164). También con decoración pintada en rojo hallamos esta jarra en la segunda fase de la necrópolis de l'Almoina fechada en el s. VII (Pascual et al. 2003: 84, Fig. 12). Pero sin duda, el ejemplar al que más se asemeja nuestra pieza es al rescatado del pecio de Saint-Gervais 2, que se fecha en la primera mitad o a mediados del s. VII (Pascual et al. 2003: 84, Fig. 12,3), fechándose entre el 400/600 d.C. Esta datación coincide con la proporcionada por nuestro enterramiento de $c a$. 400-650 d.C. En Alicante, tiene un paralelo claro en la necrópolis del $\mathrm{Pa}$ lacio Llorca: pertenece a la TB 224, tipo IIE (túmulo/ cubierta de piedras sobre lajas que se apoyan sobre banco lateral de la fosa).

Por su parte, en los elementos relacionados con la vestimenta, se produce para esta segunda fase -en palabras de Ripoll- un fuerte bizantinismo y romanismo, destacando la aparición de los broches de cinturón de tipo liriformes.

\section{FINALIZACIÓN DE SU USO:}

Parecería lógico pensar que su terminación estuviera relacionada con la llegada de los islámicos a mediados del s. VIII d.C. Sin embargo como quiera que se han documentado, por un lado, algunas tumbas más modernas en el mismo espacio cementerial de las etapas anteriores, y que por otro lado en el Sector 8 del propio yacimiento se ha excavado un asentamiento alto-medieval fechable entre mediados del s. VII e inicios del s. VIII d.C., habría que pensar que, en principio, esta necrópolis irá dejando de usarse progresivamente para desarrollar otra, esta vez mucho menor y proporcional al hábitat desarrollado entonces en el citado sector.
QUINTA ETAPA: USO RESIDUAL DE LA NECRÓPOLIS EXTENSA (finales s. VII- VIII) y NUEVA NECRÓPOLIS

Como hemos adelantado al hablar de la finalización de la cuarta fase, se documentaría ahora un uso ya residual del cementerio, debido a la aparición de un nuevo asentamiento rural, laderas arriba de la Serra Grossa (Sector 8 de nuestra excavación), al que hay que vincularle no sólo una nueva zona de enterramientos (por ahora difícil de dimensionar por estar sin terminar las excavaciones), sino incluso un posible edificio cultual, como atestiguarían dos losas talladas, reutilizadas en tumbas probablemente islámicas.

En esta etapa documentamos en una tumba de nuestra necrópolis la Botella (2124.1) de base plana, cuerpo de tendencia fusiforme, cuello hiperbólico y borde recto saliente y labio plano (fig. 23.a). Presenta un asa acintada que arranca del cuello. Pertenece a la TB 2124, tipo IA (Cubierta de lajas de piedras, que apoya sobre la fosa). El inicio de este tipo se enmarca en una fase intermedia entre la $2^{\mathrm{a}}$ y la $3^{\mathrm{a}}$ de nuestra secuencia, esto es, a finales del s. V d.C., si bien perdurará hasta la $1^{\text {a }} 1 / 2$ del s. VII d.C., momento en el que puede enmarcarse esta tumba por su botella.

También documentamos una pieza singular, por su posible connotación religiosa (¿de un peregrino?). Se trata de la Cantimplora (7160-1) de cuerpo circular, plano en la parte trasera, donde se aprecia impronta de plato; cuello corto y dos asas que salen de éste (fig. 23.b). Presenta pintura almagra formando figuras vegetales (¿espiga?) sobre el cuerpo de la pieza. Pertenece a la TB 259, tipo IB (Cubierta de lajas de piedras, que apoya sobre banco lateral o pre-fosa). Nos detendremos en esta pieza por su gran interés, por ser la única de estas características que hemos documentado en el yacimiento, así como por ser un tipo de pieza que se encuentra a caballo entre la tardo-antigüedad y el mundo islámico. Ya hemos visto que, careciendo de datación absoluta del enterramiento, y encontrándose en una tumba de un tipo tan dilatado en el tiempo, IB, caben ambas posibilidades respecto a su adscripción a un período o a otro. Es más, las tumbas islámicas encontradas junto al cementerio tardo-antiguo, presentan tipologías constructivas muy parecidas a la que nos ocupa. No sería, por último, la única tumba en la zona sacra cristiana que presentase enterramientos islámicos, eso sí, hasta ahora reutilizando tumbas con enterramientos anteriores cristianos. Los primeros precedentes romanos que tenemos del uso de cantimploras, más allá 


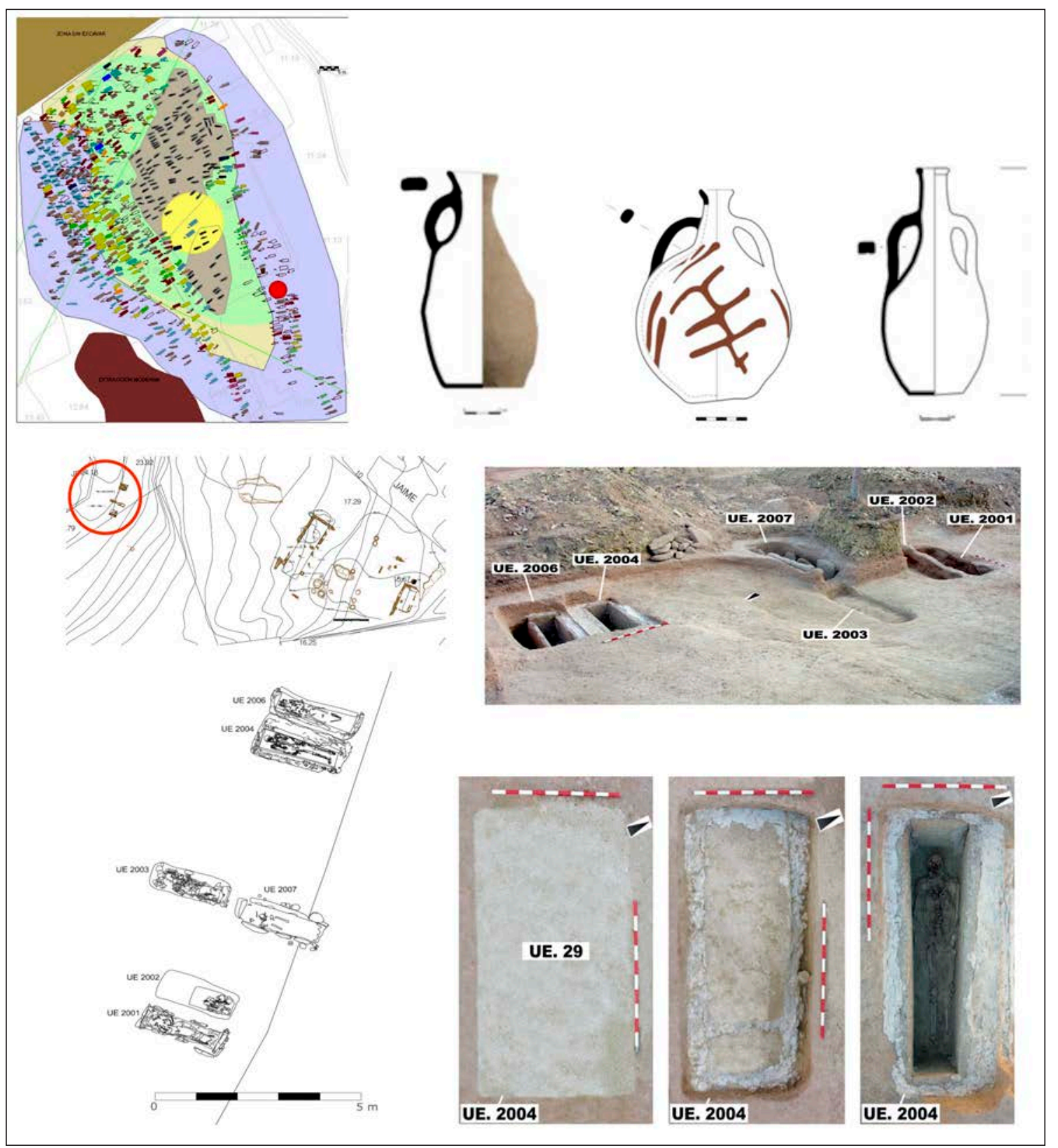

Fig. 23. Etapa alto-medieval de uso residual de la necrópolis del Tossal de les Basses. Arriba: localización de todas las etapas de la necrópolis y vasijas funerarias a, b y c. Abajo: conjunto de seis tumbas y Tumba UE 2004 de la nueva necrópolis alto-medieval.

de las formas de terra sigillata que llevan ese nombre, es en la necrópolis romana de Algeciras (Cádiz). En una tumba, se documenta una cantimplora a los pies del enterramiento. La cantimplora está realizada en cerámica común imitando el tipo Atlante 18 que se fabrica en
TSAD, y que se fecha entre el 320 y el 350 d.C. (Serrano Ramos 1993: fig. 47). La necrópolis se fecha desde finales del III y durante todo el IV. Gracias al hallazgo de una ofrenda de 18 antoninianos de Claudio II, se ha concluido que comienza a usarse durante el último cuarto del s. III, 

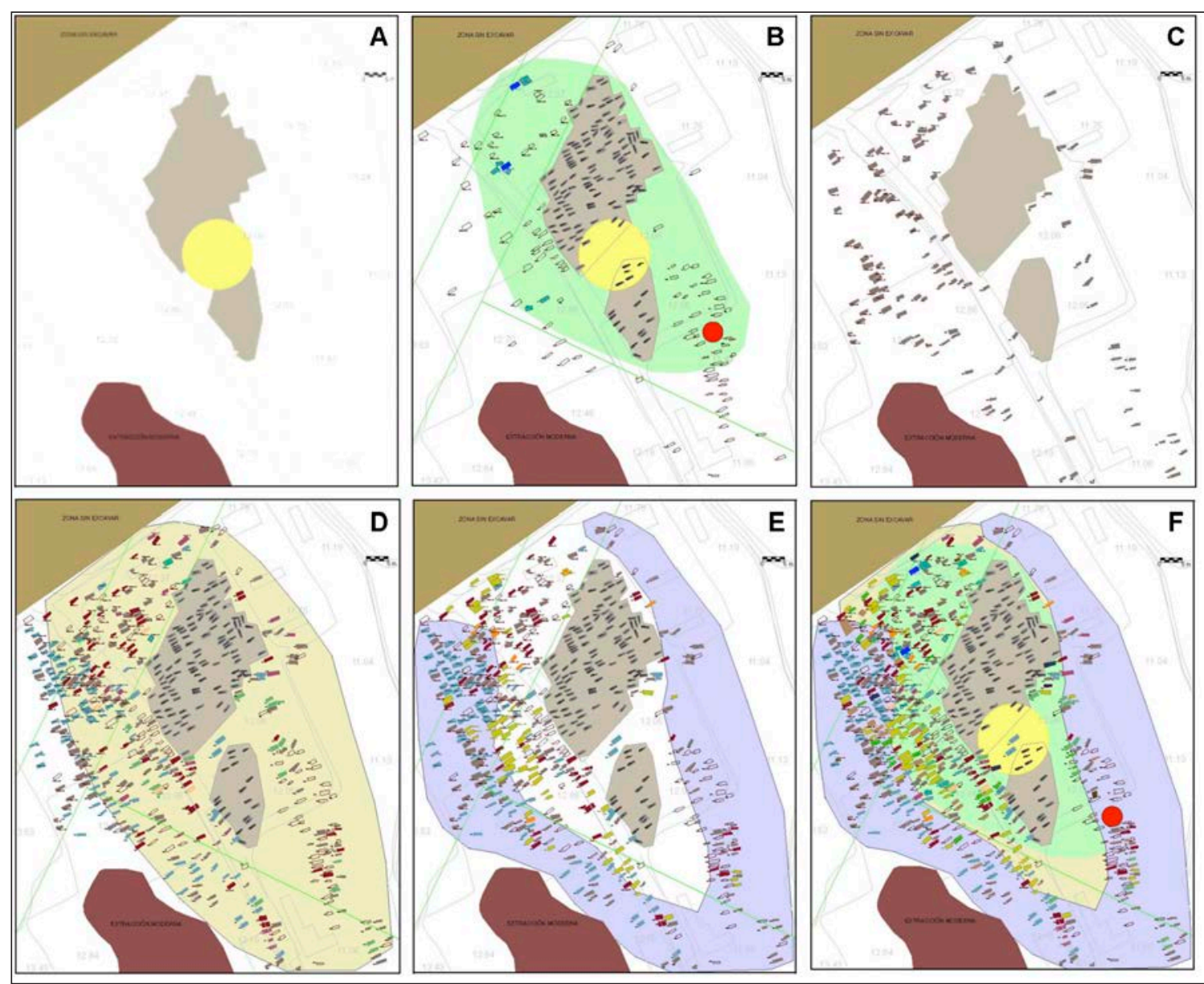

Fig. 24. Localización de todas las etapas de la necrópolis, secuencia tras secuencia. A: primera etapa. B: segunda etapa. C: etapa de transición. D: cuarta etapa ( $1^{\mathrm{a}}$ fase $)$. E: cuarta etapa ( $2^{\mathrm{a}}$ fase). $\mathrm{F}$ : todas las etapas.

en torno al año 270 (Bravo et al. 2007: 565-587). Respecto a nuestra pieza, pertenece a la forma 6/13 de la tipología de cerámicas visigodas de Izquierdo (1977: 847). Un paralelo de nuestra pieza se documenta en la necrópolis de Piña de Esgueva (Valladolid) (Pérez et al. 1932-1933; Izquierdo, 1977: 844-858). En el contexto de la Basílica Paleocristiana de Vega del Mar (San Pedro de Alcántara, Marbella), se encontró otra cantimplora (forma 11), si bien algo más estrecha que la que nos ocupa (Posac et al. 1989: 104 y 127). Para época islámica, se documenta esta forma tanto en momentos tempranos (Omeyas), como posteriores. Aparece recogida esta forma en el inventario de Rosselló (1991). Para los ss. XII-XIII se documentan estas cantimploras, también pintadas, tanto en yacimientos alicantinos como valencianos (Coll et al. 1988: 60). Sin embargo, la decoración no es la misma y su cronología se distancia mucho del contexto de nuestra necrópolis, es por ello que, como parecía lógico, adscribiremos nuestra pieza y su tumba a un momento tardo-antiguo avanzado.

Existe en otra tumba de esta etapa otra Botella (2153.1-1) de base plana, cuerpo de tendencia elipsoidal, cuello cilíndrico, borde recto engrosado exterior, y dos asas acintadas que nacen del cuello donde forman un pequeño cordón o engrosamiento (fig. 23.c). En su parte superior recuerda ligeramente al tipo 48/49 de Bonifay (con dos asas y cuello tubular), ejemplares difundidos por Bizancio y parte occidental de África, y datados en época tardía (Bonifay 2004: 285: fig. 283). Sin embargo, nuestro ejemplar tiene base plana, mientras que los citados por Bonifay tienen pie anular. En cualquier caso creemos 
haber encontrado paralelos más exactos en necrópolis visigodas, por ejemplo, de Málaga. Efectivamente, los paralelos y similitudes entre piezas de nuestra necrópolis (no sólo la que nos ocupa) y la de Vega del Mar (San Pedro de Alcántara, Málaga) (Pérez de Barradas 1932: lám. VIII, $n^{\circ}$ 7; Hübener 1965: fig. 6, nº 1), y Peñarrubia (Málaga) (Serrano Ramos et al. 1989-1990), son grandes, como seguidamente veremos. Así, en el enterramiento $\mathrm{n}^{\circ} 7$ de la necrópolis de Peñarrubia (Málaga), que pertenece al tipo B establecido por sus investigadores (esto es: fosas formadas por lajas de caliza), y que estaba cubierta con una losa de caliza de forma rectangular, se documentó un jarro de dos asas, cuello largo y fondo plano que apareció a la derecha de la cabecera. Presenta una moldura hacia la mitad del cuello, de la que arrancan las dos asas simétricas hasta la zona alta de la panza. Como decoración una franja de pequeñas incisiones en la parte superior del cuerpo. Las asas son de sección rectangular. La pasta tiene un color ocreamarillento, dura, con partículas de mica. La altura total es de $29 \mathrm{~cm}$ y el diámetro máximo en la panza de $12 \mathrm{~cm}^{8}$ y en el fondo de $8 \mathrm{~cm}$ (Serrano Ramos et al. 1989-1990: 146, lám. III, no ${ }^{\circ}$ ). Corresponde, como la nuestra, a la forma 12 en su variante Aa de Izquierdo (1977). Tiene también paralelos en otra necrópolis de Málaga, más concretamente en San Pedro de Alcántara (Hübener 1965: fig. 5, nº 5, fig. 6 , $\mathrm{n}^{\circ} 2$ y fig. $7 \mathrm{n}^{\circ} 3$ y 5), y en el Tesorillo (Serrano Ramos et al. 1985: fig. 14, $\mathrm{n}^{\circ}$ 1). Otras vasijas del depósito funerario de tumbas de la misma necrópolis, presentan el mismo tipo de moldura en cuello, reposando las asas en el, aunque varíen las formas de las piezas (Serrano Ramos et al. 19891990: lám. IV). Tipológicamente esta necrópolis tiene similitud con ciertas tumbas del Tesorillo (Serrano Ramos et al. 1989-1990: tumbas núms. 1, 3, 6, 9, 11 y 15) y con las de Villanueva del Rosario (Málaga) (Luque y Luque 1970: 557-567; Luque 1972: lám. V, no 4, 165-178). La necrópolis de Peñarrubia (Málaga) estuvo ocupada, posiblemente, a comienzos del s. V, para continuar habitado hasta finales del VII principios del VIII. Otra necrópolis visigoda en donde encontramos paralelos es la de Gózquez de Arriba (San Martín de la Vega, Madrid) (Vigil 2005; Contreras y Fernández 2006; Contreras 2006). Como hemos podido comprobar ${ }^{9}$, nuestro asentamiento alto-medieval es muy parecido al de Gózquez: modelo ocupacional del territorio a partir de pequeños espacios -¿quizá de carácter familiar?- que integran estructuras de habitación, con elementos de producción -silos, hornos, espacios abiertos asociados, etc. (Vigil 2000)-. Las tres fases en que se ha dividido, preliminarmente, el yacimiento abarcan desde inicios del s. VI a finales del mismo (fase I), el s. VII (fase II) y el s. VIII (fase III) (Vigil 1999). Como también ocurre en nuestro caso, la propia ubicación del recinto funerario de Gózquez parece indicar que los límites del área cementerial se encontraban prefijados desde el principio. El cementerio fue utilizado entre los ss. VI y VIII d.C. de forma ininterrumpida. Durante todo este tiempo se construyeron alrededor de 450 tumbas en las que son frecuentes las reutilizaciones. Es en dicha necrópolis en donde se han localizado dos ofrendas de ajuares cerámicos (tumbas 206 y 230). La que nos interesa, por su paralelismo con nuestra pieza, es una jarrita piriforme de pasta anaranjada y torno rápido, que sus investigadores incluyen en el período III del poblado, fechado como ya hemos comentado durante la segunda mitad del s. VII y el s. VIII d.C.

Volviendo a nuestra pieza, podemos decir que pertenece a la TB 2153, tipo IIE, túmulo/cubierta de piedras sobre lajas que se apoyan sobre banco lateral de la fosa.

Respecto a la nueva necrópolis, vinculada a un tipo distinto de hábitat también, hay que situarla laderas arriba de la anterior y a más de $600 \mathrm{~m}$. Se han hallado seis enterramientos humanos ocupando un área aproximada de 56 $\mathrm{m}^{2}$. Lamentablemente, debido a la existencia de construcciones modernas aledañas es imposible saber las verdaderas dimensiones de este nuevo espacio cementerial. Presentan los enterramientos una misma orientación NO-SE, y parecen estar más o menos agrupadas. Incluso, se podría considerar enterramientos con especial vínculo al menos a los grupos formados por las tumbas 2006 y 2004, y 2001 y 2002, respectivamente.

Desde un punto de vista constructivo, se diferencian respecto a los tipos que hemos descrito en la gran necrópolis, y se asemejan a enterramientos muy tardíos encontrados, por ejemplo, en Valencia y, más cercanos, en Benalúa. En cualquier caso, no se abandonan ciertas pautas introducidas en aquella, como la cubierta tumular, o las cistas, documentadas a partir, sobre todo, de la etapa $3^{\mathrm{a}}$ y que perdurarán en la $4^{\mathrm{a}}$.

Su adscripción cronológica no merece la menor duda, esto es, son de Época Tardo-antigua, no sólo por la tipología constructiva de las mismas, sino porque en la limpieza del relleno de la tumba TB7 se han recuperado dos fragmentos -fuera de contexto- de terra sigillata africana D, cuya producción data del s. VI d.C. Parece igualmente factible su asociación con los habitantes de los Edificios 1 y 2 del Sector 8b. En tal sentido, tanto para los lechos de las tumbas como para unir y enlucir las diferentes losas utilizadas en las cistas o pseudocistas se usa el yeso. El uso de este material constructivo también se documentó en los 
edificios del Sector $8 \mathrm{~B}$, a escasos $40 \mathrm{~m}$ al $\mathrm{E}$ y en una zona más baja -las tumbas se sitúan alrededor de $22 \mathrm{~m} \mathrm{~s} / \mathrm{n} / \mathrm{m}$, mientras que los edificios presenta una cota mayor de $18 \mathrm{~m}$ $\mathrm{s} / \mathrm{n} / \mathrm{m}$ y una menor de $14,5 \mathrm{~m} \mathrm{~s} / \mathrm{n} / \mathrm{m}-$. Otra conclusión es que ninguna de las tumbas contenía depósito funerario, ni los individuos portaban adornos personales, tan sólo el relleno UE. 28 del enterramiento UE. 2003 nos ha proporcionado el material cerámico datable, comentado más arriba. En concreto varios fragmentos de bordes de formas tardías de la producción terra sigillata africana D que nos indican que la construcción de esa tumba se llevó a cabo con posterioridad al inicio del s. VII d.C. Todo ello confirma que estamos ante una nueva zona cementerial, vinculada a un nuevo núcleo de hábitat y, quizá, a un nuevo edificio religioso. Efectivamente, las losas talladas (hoy conservadas en el MARQ) y que por descripciones de los años 50 debieron aparecer en las proximidades de la zona que ahora nos ocupa. apuntarían en ese sentido. El cómo interpretar este carácter de "nuevo" asentamiento que confirma el registro material, hoy por hoy y hasta que no se reanuden las excavaciones arqueológicas, se nos escapa. Hay que tener en cuenta que, eso sí está claro, estaríamos ante una comunidad cuyo desarrollo quedó interrumpido por la llegada de los musulmanes a inicios del s. VIII d.C., momento al que prácticamente llegan algunas de las cerámicas encontradas en la zona de hábitat (1/2 s. VII-inicios s. VIII), con claros paralelos en Fontcalent (Alicante), La Alcudia (Elche) y el Horizonte I del Tolmo de Minateda (Hellín, Albacete).

\section{DISCUSIÓN}

Como hemos intentado demostrar en este artículo, resumiendo el análisis pormenorizado que se realizó en su día de la necrópolis, parece evidente que estamos ante un importantísimo espacio cementerial de la tardo-antigua alicantina que, pese a su extensión y número total de individuos (cerca del millar), no se ha podido vincular con ningún núcleo urbano de importancia. Sin embargo, su situación en la línea de costa, perfectamente conectada con las tierras del interior, y la vía Augusta, por al menos dos vías de comunicación pudieron ayudar a su desarrollo.

Su importancia y excepcionalidad en la actual realidad arqueológica hispana, sobre todo en cuanto a su extensión, continuidad temporal y depósito funerario, parece igualmente demostrada, sobre todo en lo que hace referencia a contextos rurales.
Su desarrollo desde mediados del s. IV hasta la llegada de los musulmanes a inicios del s. VIII, nos ha permitido, junto con un importante número de dataciones absolutas y un nada despreciable registro material en el interior de las tumbas, profundizar en aspectos relativos a la evolución de los tipos constructivos de tumbas, su posible relación con cambios socio-políticos y de creencias. Los hallazgos en tal sentido son una novedad de importancia para Alicante que, además, tendrá su extensión -como han demostrado nuestras investigaciones en todo el término municipaltanto al actual Casco Antiguo en las laderas del Benacantil, como al barrio de Benalúa.

La posibilidad, detectada en la necrópolis, tanto de una escasa incidencia de la ocupación bizantina, junto con la probable presencia en momentos anteriores de la fecha tradicional de la llegada de los visigodos (tras la expulsión de los imperiales), abre un panorama muy interesante también al estudio del mapa geo-político de las tierras alicantinas, hasta ahora inimaginable, en el que habrá que profundizar.

Tampoco es desdeñable el haber constatado la aparición de un nuevo asentamiento y necrópolis alto-medieval en sus cercanías, con cambios profundos en el urbanismo y, por ende, en los medios de producción, registro material, etc.

Por último, pero no menos importante, es la posible reutilización de algunas tumbas cristianas en los primeros momentos de la ocupación islámica con enterramientos en decúbito lateral. Como ocurre, por ejemplo, en Marroquíes Bajos (Jaén) (Serrano Peña y Castillo 2000), en nuestro caso queda pendiente la realización de estudios específicos que determinen la posible linealidad familiar y la continuidad, o no, de los mismos grupos de poblamiento desde los rituales cristianos a los islámicos. Esa vinculación podría venir apoyada no sólo por las dataciones absolutas, sino por la documentación de una nueva necrópolis -está sí solamente islámica- pero inmediatamente contigua al espacio sacro tardo-antiguo que ahora se abandona.

En definitiva, todos los datos arriba mencionados hacen a la necrópolis del Tossal de les Basses fundamental para entender la evolución de la zona con posterioridad a la desaparición en el s. III de la ciudad romana de Lucentum.

PABlo Rosser Limiñana Departamento de Patrimonio Cultural Municipalidad de Alicante pablorosser@gmail.com

Seila Soler Ortiz Universitat d'Alacant seilaaixa@gmail.com 


\section{NOTAS}

1. Ver bibliografía en González Villaescusa 2001: 133.

2. El estudio paleo-antropológico, patológico, de denticiones y ADN ha sido encargado a especialistas, y aunque disponemos de las primeras conclusiones de sus análisis, no nos ha parecido conveniente su utilización a la espera de los estudios definitivos por sus autores respectivos.

3. Dataciones realizadas por Beta Analytic Radiocarbon Dating Laboratory. Miami, Florida. EEUU. Fechas calibradas 2 sigma con el programa INTC AL04.

4. Pese a que hemos tratado este tema en profundidad en nuestro estudio, lo omitiremos de esta publicación por falta de espacio.

5. Aunque existe una amplia bibliografía al respecto, destacaríamos los interesantísimos artículos publicados en la revista $M A S$ TIA del Museo de Cartagena, o de la revista VERDOLAY del Museo Arqueológico de Murcia, así como el monográfico: Vaquerizo et al. 2006, especialmente para la época que tratamos, el segundo volumen.

6. Hay que reseñar que la tumba TB 2139, con orientación N/S, por datación absoluta se fecha a mediados del s. III d.C. (ca. cal. 250 d.C.), lo cual la convierte -si la fecha es correcta- en una de las primeras tumbas de este área cementerial. Teniendo en cuenta que, además, se ubica en el límite por el $\mathrm{N}$ de la zona de tumbas, esa posibilidad es plausible, y habría que relacionarla, sin duda, con la villa o instalación alto-imperial que se documenta en la zona, con un torcularium y una calera. Nada más podemos decir de ella por su mal estado de conservación, pero de confirmarse tendríamos una Etapa pre-cementerio anterior a la Primera etapa.

7. El tipo IB ocupa el $16 \%$ del total de enterramientos estudiados, convirtiéndose -si excluimos al tipo 0 - en el segundo de todos los existentes, y el de mayor expansión cronológica. Respecto a presencia de depósito funerario ocupa el primer lugar con un $19 \%$. Sin embargo, ningún elemento documentado puede adscribirse cronológicamente a esta fase.

8. Por lo tanto, prácticamente igual a nuestra pieza, que tiene 27 $\mathrm{cm}$ de alto, y 12 de diámetro.

9. No podemos detenernos aquí en tan interesante hallazgo, pero es la primera vez que documentamos en la zona alicantina un asentamiento altomedieval de estas características, con claros paralelos también con el Horizonte I del Tolmo de Minateda.

\section{BIBLIOGRAFÍA}

ACIÉN, M.; CASTAÑO, J. N.; NAVARRO, I.; SALADO, J. B.; VERA, M. (2003): Cerámicas tardorromanas y altomedievales en Málaga, Ronda y Morón, Cerámicas tardorromanas y altomedievales en la Península Ibérica (L. Caballero, P. Mateos y M. Retuerce, eds.), Anejos de AEspA XXVIII, 411-454.

AZKARATE, A.; SOLAUN, J. L. (2003): Después del Imperio Romano y antes del año mil: morfología urbana, técnicas constructivas y producciones cerámicas, Arqueología de la Arquitectura 2, 37-46.

AZKARATE A.; SOLAUN, J. L. (2004): Investigaciones arqueológicas en el núcleo fundacional de Vitoria-Gasteiz. Primeros avances sobre poblamiento e indicadores cronológicos cerámicos, Vitoria.
BONIFAY, M. (2004): Études sur la céramique romaine tardive d'Afrique, BAR i.s. 1301, Oxford.

BRAVO, S.; VILA, M.; DORADO, R.; SOTO, A. (2007): Un conjunto de antoninianos de la necrópolis romana de Algeciras (Cádiz), XIII Congreso Nacional de Numismática (Cádiz, 22-24 octubre de 2007), 565-587.

CARMONA, A. (1991): De lo romano a lo árabe: el surgimiento de la ciudad de Murcia, La ciudad islámica. Ponencias y comunicaciones, Zaragoza, 291-302.

COLL, J.; MARTÍ, J.; PASCUAL, J. (1988): Cerámica y cambio cultural. El tránsito de la Valencia islámica a la cristiana, Madrid.

CONTRERAS, M. (2006): Evolución del ritual funerario entre los ss. VI y VIII d.C. en el asentamiento de Gózquez de Arriba (San Martín de la Vega, Madrid), Galia e Hispania en el contexto de la presencia "Germánica" (s. V-VII). Balance y perspectivas (J. López Quiroga, A. M. Martínez Tejera y J. Morín de Pablos, eds.), BAR i.s. 1534, Oxford, 273-288.

CONTRERAS, M.; FERNÁNDEZ, A. (2006): El espacio funerario en el poblado de época visigoda de Gózquez de Arriba (San Martín de la Vega, Madrid, La investigación de época visigoda en la Comunidad de Madrid (J. Morín de Pablos, ed.), Zona Arqueológica 8 (2), 517-536.

GONZÁLEZ PRATS, A.; ABASCAL, J. M. (1987): La ocultación monetal de la D'Eula, Crevillente (Alicante) y su significación para el estudio de las invasiones del siglo III, Lucentum 6, 183-196.

GONZÁLEZ VILLAESCUSA, R. (1990): El vertedero de la Avenida de España, 3 y el siglo III d.n.e. en Ebusus. Ibiza, Trabajos del Museo Arqueológico de Ibiza 22.

GONZÁLEZ VILLAESCUSA, R. (2001): El mundo funerario romano en el País Valenciano. Monumentos funerarios y sepulturas entre los siglos I a. de C.-VII d. de C., Madrid.

GUTIERREZ, C. (1990): Broches y placas de cinturón de época bizantina e hispano-visigoda hallados en la provincia de Málaga, $A A A$ 2, 318-325.

HALSALL, G. (1995): Settlement and social organization. The Merovingian region of Metz, Cambridge.

PÉREZ DE BARRADAS, J. (1934): Excavaciones en la necrópolis visigoda de Vega del Mar (San Pedro de Alcántara, Málaga), JSTA 128, Madrid.

HÜBENER, W. (1965): Zur chronologische gliederung des graber feldes von San Pedro de Alcántara, Vega del Mar (Provincia Málaga), Madrider Mitteilungen 6.

IZQUIERDO, R. (1977): Ensayo de una sistematización tipológica de la cerámica de necrópolis de época visigoda, Revista de Archivos Bibliotecas y Museos LXXX/4, 838-865.

LECHUGA, L. (1985): Numismática Tardorromana de la Región de Murcia, Antigüedad y Cristianismo 2.

LÓPEZ QUIROGA, J.; MARTÍNEZ, A. (eds.) (2009): Morir en el Mediterráneo medieval, III Congreso Internacional de Arqueología, Arte e Historia de la Antigüedad Tardía y Alta Edad Media peninsular, Madrid. 
LUQUE, A. D.; DE LUQUE, A. (1970): Arqueología Antequerana, XI Congreso Nacional de Arqueología (Mérida, 1968), Zaragoza, 558 y ss.

LUQUE, A. DE (1972): Necrópolis visigoda de Villanueva del Rosario (Málaga), Mainake 1, 165-178.

MURCIA, A. J.; GUILLERMO, M. (2003): Cerámicas tardorromanas y altomedievales procedentes del Teatro Romano de Cartagena, Cerámicas tardorromanas y altomedievales en la Península Ibérica (L. Caballero, P. Mateos y M. Retuerce, eds.), Anejos de AEspA XXVIII, 169-223.

MURCIA, A. J.; VIZCAÍNO, J.; GARCÍA LORCA, S.; RAMALLO, S. F. (2005): Conjuntos cerámicos tardíos de las excavaciones en el teatro romano de Cartagena, 1st International Conference on Late Roman Coarse Wares, Cooking Wares ana amphorae in the Mediterranean: Archaeology and Archaeometry (Barcelona, 2002) (J. M. Gurt i Esparraguera, J. Buxeda i Garrigós, M. A. Cau Ontiveros, eds.), BAR, i.s. 1340, Oxford, 1-36.

PASCUAL, J.; RIBERA, A.; ROSSELLÓ, M. (2003): Cerámicas de la ciudad de Valencia entre la época visigoda y omeya (siglos VI-X), Cerámicas tardorromanas y altomedievales en la Península Ibérica (L. Caballero, P. Mateos, M. Retuerce, eds.), Anejos de AEspA XXVIII, 67-117.

PÉREZ DE BARRADAS, J. (1932): La Basílica paleocristiana de Vega del Mar. San Pedro de Alcántara. Málaga, AEAArq VIII, 53-72.

PÉREZ, J.; TOVAR, A.; SUPIOT, J. (1932-1933): Avance de estudio sobre la necrópolis visigoda de Piña de Esgueva, $B S A A$ 1 (3), 253-257.

POSAC, C.; PUERTAS, R. (1989): La Basílica paleocristiana de Vega del Mar (San Pedro de Alcántara, Marbella), Colección Monografías 2, Málaga.

REYNOLDS, P. (1985): Cerámica tardorromana modelada a mano de carácter local, regional y de importación en la provincia de Alicante, Lucentum IV, 245-267.

REYNOLDS, P. (1987): El yacimiento tardorromano de Lucentum (Benalúa-Alicante): las cerámicas finas, Catálogos de fondos del Museo Arqueológico, Alicante.

REYNOLDS, P. (1993): Settement and pottery in the Vinalopó Valley (Alicante, Spain), a.d. 400-700, BAR, i.s. 588, Oxford.

REYNOLDS, P. (1995): Trade in the Western Mediterranean, $A D$ 400-700: the ceramic evidence, BAR, i.s. 604, Oxford.

REYNOLDS, P. (1996): Cerámica de carácter local, regional y de importación en el Valle del Vinalopó (Alicante). Contribución al estudio del comercio en la Tardo-antigüedad en la zona sureste de España durante los siglos V a VII, Actas de las Jornadas La sede de Elo 1400 años de su fundación, El Espacio religioso y profano en los territorios urbanos de Occidente (siglos V-VII) (Elda, 1991), Alebus 6, 217-252.

REYNOLDS, P. (2003): Spain, Portugal and the Balearics: 4th-7th century (Late roman, Byzantine and Visigothic), VIIe Congrès International sur la Céramique Médiévale en Méditerranée (Thessaloniki, 1999), Athènes, 571-585.
REYNOLDS, P. (2005): Levantine amphorae from Cilica to Gaza: a tipology and analisis of regional production trends from the 1st to 7th centuries, 1st International Conference on Late Roman Coarse Wares, Cooking Wares ana amphorae in the Mediterranean: Archaeology and Archaeometry (Barcelona, 2002) (J. M. Gurt, J. Buxeda y M. A. Cau, eds.), BAR, i.s. 1340, Oxford, 563-611.

RIBERA, A. (1992): Necròpolis romanes de la Vall d'Albaida. Breu aproximació, Estudis i Documents VIII, 61-66.

RIPOLL, G. (1985): La necrópolis visigoda de El Carpio de Tajo (Toledo), Excavaciones Arqueológicas de España 142.

RIPOLL, G. (1990): El Carpio de Tajo: precisiones cronológicas de los materiales visigodos, Jornadas Internacionales "Los visigodos y su mundo" (Madrid, 1990), Arqueología, paleontología y etnografía 4, 367-384.

RIPOLLÈS, P. P. (1980): La circulación monetaria en las tierras valencianas durante la Antigüedad, Barcelona.

ROSSELLÓ, G. (1991): El nombre de las cosas en al Andalus: una propuesta de terminología cerámica, Palma de Mallorca.

ROSSER, J. H. (1979): A research strategy for Byzantine archaeology, Byzantine Studies/ Études byzantines 6, 152-166.

ROSSER, P. (1990a): Últimos descubrimientos arqueológicos, Historia de Alicante, Fascículo 6, El Tossal de Manises y su entorno, Alicante.

ROSSER, P. (1990b): Los asentamientos anteriores al musulmán en el solar de la actual Ciudad de Alicante (Casco Antiguo): descubrimiento trascendental, LLOC INFORMATIU 1, Alicante.

ROSSER, P. (1991): Nuevos descubrimientos arqueológicos de época romana en el Término Municipal de Alicante, Historia de Alicante.

ROSSER, P. (1992A): Avance preliminar del hallazgo de pinturas y estucos decorados en la villa romana del Parque de las Naciones (Albufereta, Alicante), I Coloquio de Pintura Mural Romana en Hispania, 149-153.

ROSSER, P. (coord.) (1992b): Archivo Municipal de Alicante. Historia de una rehabilitación en el Alicante contemporáneo, Alicante.

ROSSER, P. (1992-1993): La cerámica tardorromana de producción africana en las excavaciones arqueológicas del término municipal de Alicante, Tabona VIII, Tomo II, 535-552.

ROSSER, P. (1993): El COPHIAM: síntesis de una actuación durante seis años, $L Q N T$ 1, 9-74.

ROSSER, P. (1994a): Memoria de las actuaciones realizadas en el ejercicio 1992-93 y principios de 1994, LQNT 2, 11-34.

ROSSER, P. (1994b): Nuevas aportaciones a la problemática de la antigüedad tardía en Alicante, $L Q N T$ 2, 69-110.

ROSSER, P. (coord.) (2007): El Patrimonio Cultural de Alicante: Avance de un Catálogo. El Patrimonio Inmueble, LQNT Monográfico 3.

ROSSER, P. (2013): Arqueología del poblamiento de un territorio del Mediterráneo Occidental (Alicante, España) desde época tardo-antigua a la primera ocupación islámica. Un espacio activo sin ciudad: de villas a pre-aldeas, Tesis Doctoral, Universidad de Alicante. 
ROSSER, P.; FUENTES, C. (2008): Seis mil años de historia de Alicante: El Tossal de les Basses, Alicante.

ROSSER, P.; PÉREZ BURGOS, J. M.; ROBEY, D. (1992): La eXcavación arqueológica de la necrópolis de la calle Labradores esquina San Isidro (Palacio 'Llorca “, Casco Antiguo, Alicante). Avance preliminar, Archivo Municipal de Alicante. Historia de una rehabilitación en el Alicante Contemporáneo, Alicante, 17-28.

SERRANO PEÑA, J. L.; CASTILLO J. C. (2000): Las necrópolis medievales de Marroquíes Bajos (Jaén). Avance de las investigaciones arqueológicas, Arqueología y Territorio $\mathrm{Me}$ dieval 7, 93-120.

SERRANO RAMOS, E. (1993): Sigillatas africanas del Teatro Romano de Málaga, Estudios dedicados a Alberto Balil in memoriam, Málaga, 83-111.

SERRANO RAMOS, E.; ATENCIA, R.; LUOUE, A. DE (1985): Memoria de las excavaciones del yacimiento arqueológico de "El Tesorillo" (Teba, Málaga), NAH 26.
SERRANO RAMOS, E.; LUQUE, A. DE; SOLA, A. (1989-1990): Arqueología malagueña: el yacimiento de Peñarrubia, Mainake 11-12, 139-157.

VAQUERIZO, D.; GARRIGUET, J. A.; LEÓN, A. (eds.) (2006): Espacio y usos funerarios en la ciudad histórica, Córdoba.

VIGIL,A. (1999): Evolución de los morfotipos de cerámica común de un asentamiento rural visigodo de la Meseta (Gózquez de Arriba, San Martín de la Vega, Madrid), Revista Arquehispania 0, (http:// www.arqueohispania.com/journal/num0/not1.html).

VIGIL, A. (2000): Cabañas de época visigoda: evidencias arqueológicas del Sur de Madrid. Tipología, elementos de datación y discusión, AEA 73, 245-274.

VIGIL, A. (2005): Nuevas perspectivas sobre la arqueología madrileña de época visigoda, I Jornadas de Patrimonio Arqueológico en la Comunidad de Madrid, 169-181.

VIZCAÍNO, J. (2009): La presencia bizantina en Hispania (siglos VI-VII). La documentación arqueológica, Antigüedad y Cristianismo XXIV, Murcia. 